University of Nebraska - Lincoln

DigitalCommons@University of Nebraska - Lincoln

Mechanical \& Materials Engineering Faculty

Publications

Mechanical \& Materials Engineering,

Department of

2007

\title{
A Scientific Foundation of Collaborative Engineering
}

S. C.-Y. Lu

University of Southern California, Los Angeles, sclu@usc.edu

W. ElMaraghy

University of Windsor, wem@uwindsor.ca

G. Schuh

Aachen University RWTH, g.schuh@wzl.rwth-aachen.de

R. Wilhelm

University of North Carolina at Charlotte, bob.wilhelm@unl.edu

Follow this and additional works at: https://digitalcommons.unl.edu/mechengfacpub

Part of the Mechanics of Materials Commons, Nanoscience and Nanotechnology Commons, Other

Engineering Science and Materials Commons, and the Other Mechanical Engineering Commons

Lu, S. C.-Y.; EIMaraghy, W.; Schuh, G.; and Wilhelm, R., "A Scientific Foundation of Collaborative Engineering" (2007). Mechanical \& Materials Engineering Faculty Publications. 412.

https://digitalcommons.unl.edu/mechengfacpub/412

This Article is brought to you for free and open access by the Mechanical \& Materials Engineering, Department of at DigitalCommons@University of Nebraska - Lincoln. It has been accepted for inclusion in Mechanical \& Materials Engineering Faculty Publications by an authorized administrator of DigitalCommons@University of Nebraska Lincoln. 
Published in Annals of the CIRP 56:2 (2007), pp. 605-634; doi: 10.1016/j.cirp.2007.10.010

Copyright (C) 2007 Elsevier Ltd. Used by permission.

Published online November 22, 2007.

\title{
A Scientific Foundation of Collaborative Engineering
}

\author{
S. C.-Y. Lu, ${ }^{1}$ W. ElMaraghy, ${ }^{2}$ G. Schuh, ${ }^{3}$ and R. Wilhelm ${ }^{4}$
}

1. University of Southern California, Los Angeles, California, USA

2. University of Windsor, Windsor, Ontario, Canada

3. Aachen University RWTH, Aachen, Germany

4. University of North Carolina at Charlotte, Charlotte, North Carolina, USA

\section{Dedication}

We respectively dedicate this keynote paper to our late colleague and esteemed mentor Dr. M. Eugene Merchant, whose distinguished life and career inspired us to embark on an ambitious quest for new paradigms in production engineering.

\begin{abstract}
Collaborative engineering is the practical application of collaboration sciences to the engineering domain. In today's highly connected technology-driven economy, the production industry must rely on the best practices of collaborative engineering to stay competitive when designing, manufacturing, and operating complex machines, processes, and systems on a global scale. Despite its importance, collaborative engineering is currently more of a practiced art than a scientific discipline. A better understanding of how engineers should collaborate with all stakeholders to accomplish complex tasks that fulfill our increasing social responsibilities is a grand challenge. However, because we currently lack well-defined sciences of human collaboration, we must first establish a scientific foundation of collaborative engineering to develop this emerging field into a rigorous discipline. This paper reports on the CIRP community's collective efforts to establish such a scientific foundation according to the "Observation $\rightarrow$ Hypothesis $\rightarrow$ Theory" development pathway. Our objective is to spearhead the rigorous development of this new human-centered engineering discipline so that useful knowledge can be generated to educate students and practical guidelines can be developed to enable engineers to become more productive collaboration leaders in the new global production industry.
\end{abstract}

Keywords: design, manufacturing, collaboration 


\section{Introduction}

Engineers create functional and purposeful artifacts, including technical products, services, and systems, to fulfill changing societal needs. The never-ending demands for better function, lower cost, higher quality, shorter lead-time, and increasing social responsibilities have made engineering a very demanding profession. For example, today's production engineers are often asked to design, manufacture, and operate complex machines and processes that cannot be effectively addressed by any conventional ways. In these cases, production engineers with complementary expertise and resources must work with many stakeholders who have competing interests to reach technical agreements that can simultaneously satisfy multiple objectives. Recent trends in lifecycle engineering and market globalization have introduced additional challenges into the production engineering profession. The desire for incorporating multiple lifecycle considerations calls for tighter integration of diverse knowledge, and hence favors collocation of engineers [1]. Meanwhile, market globalization necessitates that engineering teams be decentralized and distributed around the world to be close to local customers [2]. This "integration vs. distribution" paradox calls for new approaches that can facilitate the creation of "shared minds among multiple stakeholders" within and/or across engineering organizations. This is the goal of the field of "collaborative engineering" [3]. The aim of this emerging human-centered discipline is to enable engineers and engineering companies to work more effectively with all stakeholders in achieving rational agreements and performing collaborative actions across various cultural, disciplinary, geographic, and temporal boundaries. In today's global production industry, good collaborative engineering practice can improve task-work results with rewarding teamwork experiences, which can greatly improve the competitiveness of production engineering enterprises in both the short- and long-term.

Collaboration is the process of multiple people working together interdependently to achieve a greater goal than is possible for any individual to accomplish alone [4]. Although the concept is as old as human civilization, collaboration is often taken for granted, overlooked, misunderstood, and poorly accomplished in practice. In a fully connected society, collaboration is ubiquitous in all professional activities, ranging from technical projects for business pursuits to international efforts such as space exploration and combating global warming. Despite its great importance, we lack fundamental knowledge about human collaboration and its underlying sciences. For example, in current industry practice, collaboration occurs at all phases and has become an integral part of any engineering project. Although we can recognize the good results of successful collaborations, our ability to recreate the desired collaboration process and train engineers to better collaborate with each other is still very limited [5]. Failure to understand this important activity has led to many harmful consequences and economic losses in the industry. As complexities and demands of the engineering profession increase rapidly, poor collaborations often result in major project breakdowns, long time delays, huge resource wastes, and high rework costs, which hinder our industry's ability to remain competitive in the dynamic global market.

To support the global competitiveness of our industry, we must transform collaborative engineering from "a black art practiced by the few" to "a rigorous discipline understood 
by the many." A direct way to study collaborative engineering is to begin with collaboration sciences; however, there currently are no consolidated sciences of human collaboration. Worse yet, research in this area have been hindered by resistances based on a strict deterministic philosophy of traditional sciences as well as misunderstandings resulting from some early works. For example, some consider human collaboration to be an acquired social skill that belongs to the "practice of the trade" and hence can never be studied scientifically. They insist that "if one can't first provide complete mathematical proof of existence, uniqueness, stability, and convergence properties of collaboration, then there is no intellectual substance to collaborative engineering research" [6]. We disagree with this opinion. First, we are not convinced that mathematical models alone, at least the kinds that are based on traditional mathematics, would be adequate to deal with a dynamic sociotechnical subject that is so driven by group interactions and influenced by human preferences [7]. Second, we do not believe that "because a rigorous mathematical theory does not yet exist, the subject cannot be dealt with seriously or systematically." In fact, an examination of the history of technology development will reveal that many important engineering subjects were rigorously studied and actively practiced by engineers long before their scientific theories and mathematical proofs were available. Had we waited for rigorous mathematical proofs of thermodynamic laws before making combustion engines, we would most likely still be riding on horseback today. The scientific community should take an openminded stance toward collaborative engineering, so that innovative thinking, alternative theories, and different approaches can be explored to address this challenging subject [8].

A major confusion in collaborative engineering research comes from an old myth in social choice studies [9], which states that "group decision-making is inherently chaotic because there is no rational means to derive a consistent group preference from individual preferences." As a result, some researchers have argued that the only scientifically viable means to achieve a group decision is to rely on a "supra decision maker" who takes members' interests into consideration and makes an autocratic decision for all [10]. This means that the opportunity for engineers to actively participate in making joint decisions and rational agreements, which is the principal benefit of collaborative engineering, would be unilaterally taken away. This would result in a human collaboration problem being hastily reduced to a multi-attribute decision task [11]. Another obstacle stems from a misunderstanding by some researchers who treat collaborative engineering, in a mathematical sense, as a "cooperative game." But, according to the formal definition of game theory research [12], a cooperative game is one in which any cooperation is enforceable by an outside party. As such, collaborative engineering practice can be either a cooperative or a noncooperative game, depending on the "enforceability" of collaboration results, rather than on the members' collaborative behaviors. Thus, cooperative game strategy alone is not sufficient as the scientific foundation for collaborative engineering research. Further, games do not adequately capture all types of engineering collaboration activities in industry practice. For example, while multiple players interact to make separate decisions in games, engineers often must work together to reach a single joint decisions in teamwork. Achieving consensual agreements through joint decisions is the hallmark of collaborative engineering, which is not the focus of game research. 
Short of well-established collaboration sciences and in view of existing misunderstandings, how can we pursue the necessary scientific knowledge to develop a theory (or theories) of collaborative engineering? To answer this question, we need to consider whether, and in what way, knowledge of human collaboration is fundamentally different from that in other scientific fields, as well as whether, according to the criteria of "normal sciences," there could be a collaborative engineering theory and what it would encompass. Since collaborative engineering is a "human-centered" technical activity, its research must incorporate the sciences of the natural (e.g., physics) and of the artificial (e.g., preferences) [13]. The required paradigm shift [14], broad trans-disciplinary knowledge, and strong cross-functional requirements have made collaborative engineering studies very difficult and mostly ad-hoc to date. Replacing these informal investigations with a scientifically grounded rigorous foundation to effectively guide collaborative engineering research is the grand challenge we face today [15].

\subsection{The ECN Working Group at CIRP}

As an international research organization that prides itself on system-level subject with human-centered approach to production engineering, the Scientific and Technical Committee on Design (STC-Dn) in CIRP took on this grand challenge by establishing a new working group (WG) on "Engineering as Collaborative Negotiation" (ECN) in 2003 [16]. Initially, this CIRP/ECN-WG was formed to study the collaborative negotiation tasks that commonly take place in large engineering projects. Our original intention was to investigate different engineering group decision-making activities from a "negotiation" viewpoint, which represents a different paradigm than those existing approaches that are based on deterministic optimizations. However, after some preliminary studies, we soon realized that ECN was an expansive concept that could serve as a basic research hypothesis for the participative joint decision making task in collaborative engineering. Since then, we have adapted the notion of collaborative negotiation as a "means" to realize the "goal" of collaborative engineering. Consequentially, we modified the original ECN acronym to "Engineering Collaboration via Negotiation" to better characterize the scope of our research efforts [17]. As such, the current focus of the ECN-WG is to employ ECN as a research hypothesis to explore various participative joint decision principles and practices in collaborative engineering [18].

This keynote paper is part of the collective efforts of the CIRP/ECN-WG during its first three years. The proposed scientific foundation follows the development pathway commonly used in other scientific studies. Whether or not this pathway can eventually lead to a "science of collaborative engineering," at least to the kind of "normal science" with which engineers are most familiar, we believe that our efforts will improve the understanding of this important subject and enhance the effectiveness of its industrial practices. Rather than debating whether there is an "exact science" of collaborative engineering, our goal is to spearhead the rigorous development of this human-centered engineering field so that useful knowledge can be generated to teach students and practical guidelines can be developed to help engineers become better collaboration leaders in the new global economy. 


\subsection{A Collaborative Engineering Problem Roadmap}

Because of the lack of a clear understanding of the discipline, many projects that involve real engineering collaboration do not bear the name of collaborative engineering, while many methods and tools that carry the label of collaborative engineering do not tackle the core issues of engineering collaboration. Thus, it is necessary to define a roadmap to guide in-depth investigations of this broad subject. Based on the required knowledge types and decision styles for their solutions, we have developed a problem roadmap to define the scope of collaborative engineering studies (Table 1).

Table 1. Collaborative engineering problem roadmap

\begin{tabular}{lcc}
\hline Roadmap & $\begin{array}{c}\text { (Brute Reality) } \\
\text { Sciences of the Natural }\end{array}$ & $\begin{array}{c}\text { (Social Reality) } \\
\text { Sciences of the Artificial }\end{array}$ \\
\hline Decision Style / Knowledge Type & Preference-Neutral Knowledge & Preference-Drive Knowledge \\
\hline Individual and Isolate Decision & Optimization of a system & Classical decision \\
& of government equations & (preference) analyses \\
Interactive and Separate Decision & Optimization with multiple & (Non-cooperative) game \\
& objectives and criteria & and theoretic approaches \\
Joint and Collective Decision & Exploration of definitions, & Co-construct and negotiate \\
& objectives, and criteria & satisfactory agreements \\
\hline
\end{tabular}

Two kinds of problems are identified according to their required knowledge types [19]. Solutions for the first kind involve only deterministic knowledge that is independent of human preferences (i.e., preference-neutral). Solutions for the second kind entail socially constructed knowledge derived from human perspectives and interactions (e.g., preferencedriven). These solutions only remain "valid" when there are consensual agreements among stakeholders. The Roadmap also defines three different decision styles: an individual makes a single decision in isolation (one person, one decision), several individuals interact and make separate decisions (multiple persons, multiple decisions), and many individuals interact to achieve an agreement (multiple persons, one decision).

If one person makes a decision based on preference-neutral knowledge, mathematical optimizations of system equations derived from science-based domain models are the common approach to take [20]. When this person makes one decision in isolation with preference-driven knowledge, he/she can use classical decision techniques that provide rigorous analyses of preferences and risks [21]. When several persons interact to make separate decisions using preference-neutral knowledge, advanced multiple attribute (or objective) optimization methods are needed to handle these manifold problems [22]. If preference-driven knowledge is involved, these persons can employ approaches from noncooperative game theory to find the optimal decision strategy for themselves [12]. Many existing approaches (see Section 3) have already addressed these problems thoroughly.

The roadmap shows that the joint and collective decision is needed for both preferenceneutral and preference-driven knowledge. Collaborative engineering approach is most relevant and important here. Even for problems that are based on preference-neutral knowledge, the tasks could be highly complex and not completely structured so that joint efforts from multiple individuals would be needed to collaboratively explore the problem definitions, 
solution objectives, and evaluation criteria. Finally, when problems are preference and opinion based, many individuals must engage in collaborative negotiating to reach a consensual agreement that is satisfactory to all. These problems are the most important challenges in production engineering and the focus of our collaborative engineering studies.

\subsection{The Structure of the Scientific Foundation}

Without well-established human collaboration sciences to support collaborative engineering research, we need a foundation that conforms to the rigorous requirements and methods of scientific pursuits to support our research. A useful scientific foundation must have a logical structure (i.e., development pathway) to ensure the scientific rigor of the studies [14]. The foundation should also offer some carefully synthesized concepts and frameworks that can provide the research community with guidelines by which to study the subject scientifically. With this scientific foundation, theoretical development, practical validation, and continuous improvement of the domain knowledge and rigorous theories can take place systematically and be used to advance understandings of the field. Figure 1 shows the structure and key elements of our scientific foundation of collaborative engineering. Specific section numbers are included in this figure so that it can serve as a "graphical table of contents" for the paper.

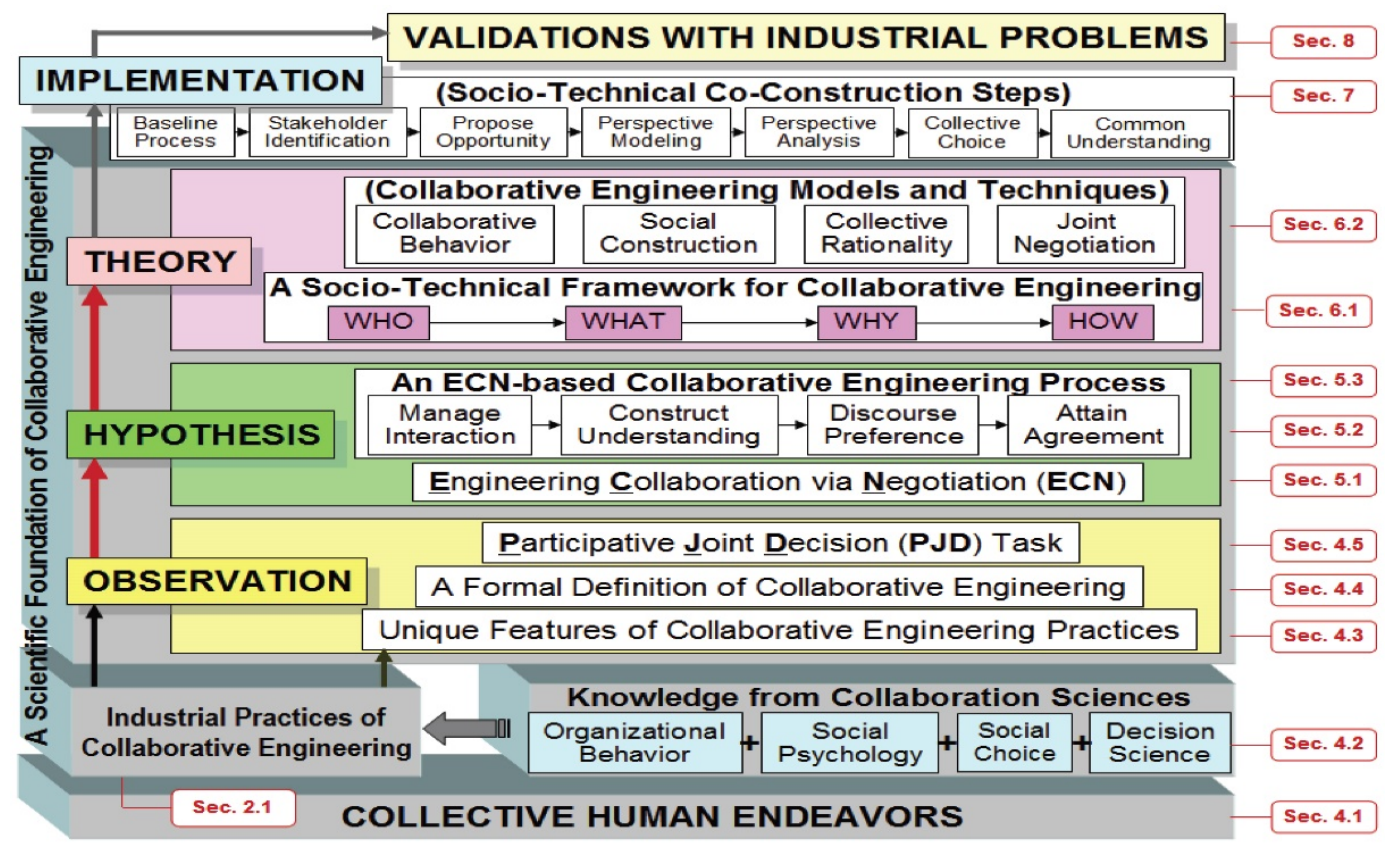

Figure 1. The structure and key elements of a scientific foundation of collaborative engineering

This scientific foundation follows the "Observation $\rightarrow$ Hypothesis $\rightarrow$ Theory" development pathway commonly used in many scientific studies [23]. The key elements (i.e., concepts and frameworks) are organized according to this three-layered structure. The 
"Observation" layer consists of our observations of the current challenges and practices of engineering team, a collaborative engineering definition, and an explanation of the participative joint decision task that is the focus of our research. The next layer includes the ECN research hypothesis and a new collaborative engineering process derived from this hypothesis. This layer also clarifies how the dynamic collaborative engineering process can lead to rational joint decisions. Anchored by this ECN hypothesis, the "Theory" layer begins with a socio-technical framework for collaborative engineering that follows the "WHO $\rightarrow$ WHAT $\rightarrow$ WHY $\rightarrow$ HOW" cycle to attain a team agreement [24]. This layer also contains needed theoretical models and practical techniques for understanding collaborative behaviors, managing social constructions, aggregating team preferences, and supporting joint negotiations [25].

\subsection{Organization of the Paper}

The intended readers of this paper are production engineering researchers, analytically minded industrial managers and practitioners, and engineering students interested in collaborative engineering. The paper begins with an assessment of present industrial practices in Section 2, followed by a review of current approaches and related CIRP activities in Section 3. Next, we present the necessary background knowledge and key concepts of collaborative engineering research in Section4. Section 5 presents the ECN hypothesis as a means to accomplish participative joint decisions in collaborative engineering practice. An explanation of how this dynamic process can meet the requirements of a rational decision is included.

Our theoretical development begins in Section 6 with a Socio-Technical Framework (STF) for collaborative engineering. The needed theoretical models and practical techniques to instantiate the STF are discussed. Sociotechnical co-construction steps are explained in Section 7 as an implementation example to make the above ECN-based collaborative engineering process operational. We also include an example research approach that models stakeholder social interactions and evolving perspectives in engineering teamwork. An industrial case study is presented in Section 8 to validate our research approach. Section 9 concludes the paper with a summary that emphasizes the urgent need for and potential impact of this exciting new discipline in production engineering.

\section{Collaborative Engineering in Industry}

Existing collaborative engineering practices in production industry are too numerous to count [26]. Some of them are at the organizational level, while the majority has been used for technical support. Despite the lack of scientific maturity of the discipline and the difficulty in assessing Returns on Investments (RoIs), some applications are regarded as quite successful in terms of tangible cost savings and productivity enhancements to organizations. Unfortunately, there are also many other attempts that are costly and have not resulted in measurable advantages over traditional practices [27]. To provide an appropriate setting for research, it is instructive to first examine the current industrial practices and challenges of collaborative engineering. Section 2.1 explains the practical needs for better collaborations as the production industry becomes global. Section 2.2 describes the benefits 
of collaborative engineering in various industry sectors to illustrate the potential impact of this practice. Section 2.3 characterizes the challenges of collaborative engineering practices to show the urgent need for additional research. Section 2.4 summarizes the features of successful collaborative engineering projects to guide our research efforts. We should note that many of the industry application projects mentioned here may not bear the name of collaborative engineering explicitly. But, their development focuses all closely relate to the goal of supporting and enhancing engineering collaboration among multiple stakeholders.

\subsection{Practical Needs for Collaborative Engineering}

In today's highly competitive industrial environment, no individual can accomplish production engineering tasks alone. Collaboration is necessary at every technical and organizational level. The needs for collaborative engineering can be best appreciated by examining the amount of collaborative efforts required by large-scale development projects that involve many distributed stakeholders. A good example is the development of the Airbus aircraft by multiple companies from different European countries [28]. Figure 2 shows the responsibilities of five countries that must work together as main contractors to deliver a complex, functional, reliable, and competitive product. On average, up to 39 nationalities could be involved as subcontractors and vendors in one such large aircraft development program.

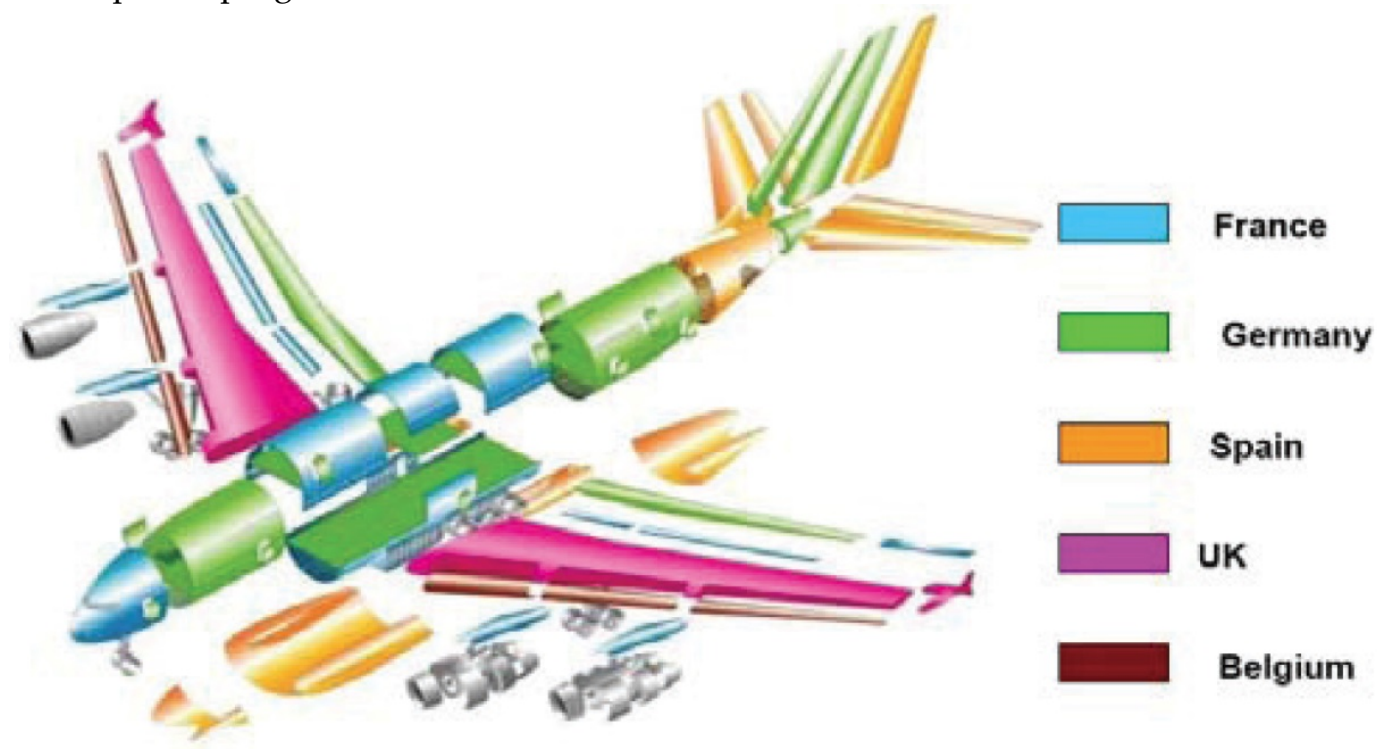

Figure 2. An example large development project [28]

Besides collaborations at the organizational level across national borders, much technical collaboration also occurs within the company. For example, to deliver an aircraft fuselage, engineers responsible for various subsystems must work together to come up with an integrated design that can accommodate the crew and the passengers or the cargo. The red color in Figure 3 indicates areas where multiple stakeholders with different responsi- 
bilities must collaborate in making joint decisions to attain agreement on respective subsystem designs. Besides these intracompany collaborations, engineers also must engage in intercompany collaborations with various stakeholders from different companies and countries to ensure that the fuselage will work with other aircraft subsystems. It was reported that about $26 \%$ of project meetings of Airbus contractors involve international partners [28]. More than 400 one-day trips are taken by Airbus engineers to collaborate with stakeholders on a daily basis.

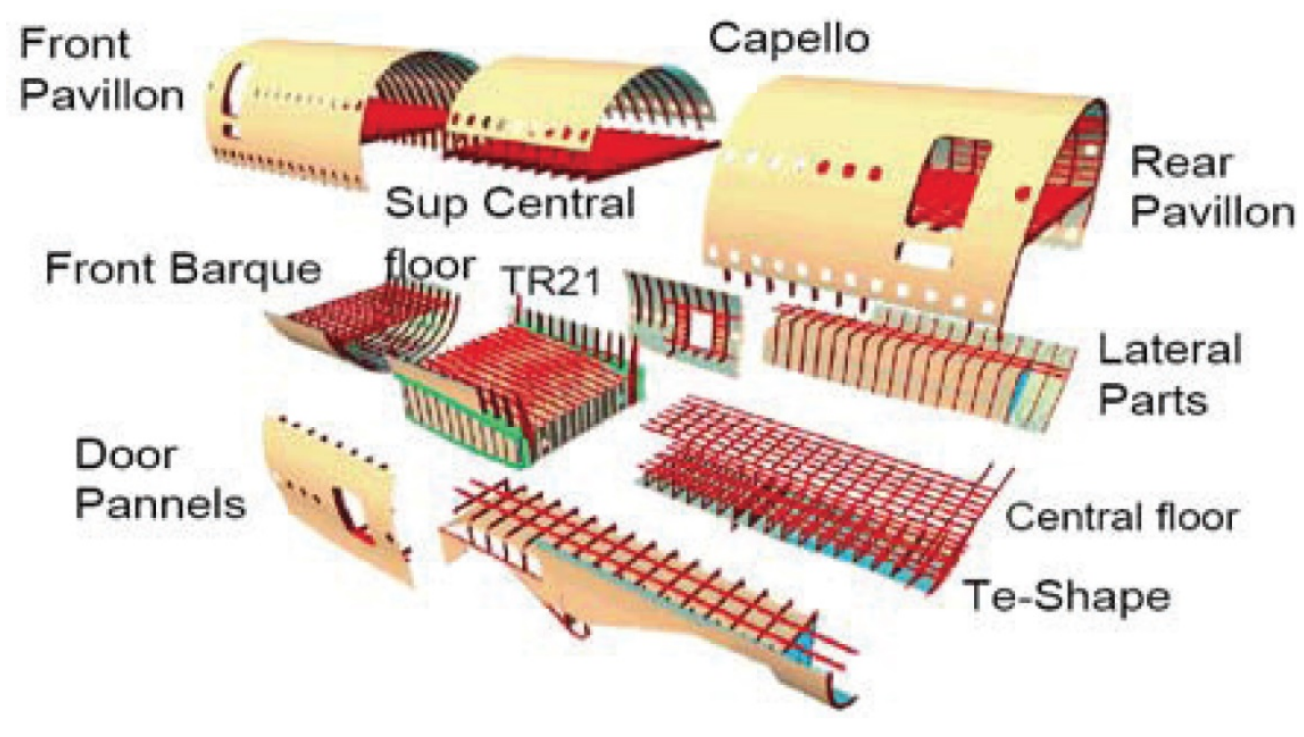

Figure 3. Collaboration among aircraft subsystems [28]

Faced with these demanding collaboration tasks, it is interesting to note that meetings are still the most common method of collaborative engineering activity in industry to date. For example, Airbus engineers spend an average of $49 \%$ of their daily activities in meetings and discussions with other stakeholders [28]. Paper documents and electronic files, such as email records, are still the standard for supporting these technical meetings. It was reported that $50-80 \%$ of the documents used in these meetings are in paper form and that $70 \%$ are for multicultural working sessions only. In short, engineering has become a highly collaborative activity in industry today, but engineering collaboration knowledge and tools are still very poorly developed.

\subsection{Benefits of Collaborative Engineering}

Effective collaboration supports can, for example, help resolve conflicts early in the design stage and reduce product development lead-time and manufacturing costs. Some companies have used collaborative computer tools to realize measurable benefits. For instance, by using a collaborative design tool to develop laser printers, Canon achieved significant reductions in design iterations, total costs, and lead-time [29]. Hewlett-Packard reported a $135 \%$ RoI after 1 month and $240 \%$ RoI after 3 months in travel costs alone, associated with 
their global product development projects [29]. Typical benefits that industry can expect from successful collaborative engineering applications fall into two categories: teamwork (i.e., process) paybacks and task-work (i.e., result) paybacks. Improvements to teamwork include better communication between team members, possibility of remote teamwork, shared understandings, collaborative generation of new ideas, fast turnaround on collective decisions, improved respect and appreciation among team members, and improved employee morale and responsibilities. Some positive impacts on task-work are shortened development time, improved product innovation, better technology integration and utilization, increased product and process quality, enhanced total value, and lower development and production costs. The following examples further illustrate some of these values and benefits in industry [18].

Silicon Graphics has used intranet infrastructure to support its global product development teams, including the interactive TV group, located in Orlando and Tokyo, and the computer chip design team, located in Japan, Switzerland, and California [18]. Collaborative engineering teams are able to get their products to market more quickly with higher quality and reduced time and costs. To enhance collaboration, National Semiconductor used collaborative engineering approaches in its distributed engineering and business practices [18]. The reported benefits include accelerated development process, faster deployment and distribution, closer to local customers and markets, and better connections among company's innovators. McDonnell Douglas (now Boeing) used collaborative engineering approaches to improve its distribution and synchronization of product information between multiple development sites and with its outside suppliers and customers [18]. Thiokol, which is a major supplier for NASA's Space Shuttle program, employs approximately 3,600 engineers at its 19,000-acre Ogden, Utah, propulsion manufacturing facility [18]. Collaborative engineering approaches helped the company to achieve efficient sharing and exchange of engineering data among divisions in this complex. Iomega, a leading producer of computer storage devices, had at one time developed products on many separate CAD workstations, without the benefit of integration [18]. Engineers wasted efforts in costly iterations to iron out conflicts that resulted from technical decisions made by different groups without collaboration. With collaborative engineering practices, it was able to achieve a $50 \%$ reduction in development time. Boeing has used digital preassembly and virtual reality tools to explore complex aircraft models during design stages [30]. Adding the collaborative engineering practice into advanced CAE environments, the company was able to enable distributed teams to reduce product development time. Many more examples of collaborative engineering applications that have brought out tangible benefits can be found in various industries today.

\subsection{Challenges of Collaborative Engineering}

When counting the name designations used by computer tools available on the market, there seems to be no shortage of collaborative engineering solutions today. However, a closer check of these "solutions" reveals that many of them are not addressing the real collaborative engineering challenges faced by industry. The problems for which the collaborative engineering approach is the most important in industry have the following characteristics: 
1. The problems are always ill defined (i.e., solutions depend on problem formulations; hence, there are disagreements about how to define the problems).

2. Due to various resource and knowledge limitations, the problems are open-ended and characterized by technical complexities and/or scientific uncertainties.

3. Unilateral efforts using traditional methods to deal with the problems have proved insufficient and have typically produced less than satisfactory solutions.

4. Several stakeholders have a vested interest in the problems, and they are interdependent of each other in needed resources and expertise for the solutions.

5. These stakeholders are not organized in a structured way, and they often have a disparity of power and/or resources for dealing with the problems at hand.

6. The stakeholders have diverse interests, expertise, and access to information about the problems; hence, they often perceive the problems differently.

7. These differing perspectives often result in, at least initially, incompatible (or adversarial) opinions and positions among the stakeholders.

We observe that there are at least three challenges that prevent effective engineering collaboration in industry. The first challenge is that a group of engineers tries to solve a problem without ever clearly defining "what the problem is." If the problems were better defined and their definitions were fully shared, stakeholders might choose different options than those based on their original assumptions and initial intentions. The second challenge is that when a group of engineers tries to address the "how" to achieve "what" (a typical task-work) question, they may not have the same set of information [31]. As a result, stakeholders argue with each other, based on different understandings. The collaboration would be a lot easier if they first collected the same set of information and developed a shared understanding. The third challenge with current industry practice is that engineers do not understand, or agree with, the "rule" for decision-making [32]. When only one of the stakeholders does not understand the "rule" that individual can create havoc with group activities. When more do not understand, the situation is worse. Ultimately, when stakeholders do not correctly understand the rules, they will have a hard time reaching a robust and sustainable agreement. The ECN-based collaborative engineering process (Section 5.2) is designed specifically to address some of these practical challenges.

\subsection{Features of Successful Industry Practices}

The first step in "Observation $\rightarrow$ Hypotheses $\rightarrow$ Theory" development pathway is to carefully observe and examine various successful collaborative practices of engineering teams in production industries. Over the past few years, we have been actively working with different collaborative engineering teams, both as participants and observers, addressing a wide range of technical tasks with different stakeholders. We have observed some highly effective collaborative engineering teams that can consistently deliver high-quality results and enjoy collaboration experiences. We have noted that the members of these successful teams and organizations share some common beliefs: (1) making joint decisions is both desirable and possible; (2) the consequences (i.e., payoffs) of joint decisions are better than 
those of individual decisions; (3) it is possible to have full, open, and truthful exchanges and communication; and (4) all participants can be creative in terms of both value creation and value claiming when making joint decisions. These real-world observations provide us with a deep understanding of, and help us to develop unique insights into, the best collaborative engineering practices. The features of successful collaborative engineering practices in industry are presented below to guide our research.

\subsubsection{Socially mediated technical activity}

The first feature is our recognition that collaborative engineering, because of its focus on reaching agreement on technical issues, must be treated as a socially mediated technical activity. Social scientists have long understood that human behavior dynamics have an impact on technical decisions that cause societal changes, which, in turn, shape human and social dynamics to influence future technical decisions. Such adaptive, cyclic, sociotechnical interactions are the true fabric of a modern technology-based society [143]. Traditional engineering approaches, which focus on individual decisions, are unable to consider this important social dimension, and hence they can only approximate collaborative engineering as a pure technical activity. The inability to include social interactions as an integral part of technical decisions is a significant roadblock to collaborative engineering studies that must be removed.

\subsubsection{Conscious and purposeful human activity}

The second feature comes from our observation that when trying to reach agreement over a common goal, engineering teams always engage in collaborative activities in a dynamic socio-technical environment. Here, an "activity" is defined by CHAT as a conscious and purposeful human endeavor driven by an individual's perspectives (e.g., interest, motive) [145]. As explained in Section 4.1, this theory suggests that collective human activities are of three kinds: coordination (e.g., planning each other's activities for sequential dependency), cooperation (e.g., taking each other's decisions into consideration for reciprocal reliance), and collaboration (e.g., constructing a new understanding and solution, i.e., dependencies based on shared knowledge). Based on our direct observations of many engineering tasks, the most effective and valuable collaborative engineering teams are those that are able to address the "construction" kind of human collaboration (see the last distinctive feature in Section 4.4.5).

\subsubsection{Full participation via co-construction process}

The third feature is that the above construction task requires direct contributions from all stakeholders to fully participate in the group decision-making process. We have also noted that these highly participative tasks are best carried out by a dynamic co-construction process (Section 6.1), whereby everyone is simultaneously and reciprocally influencing (i.e., coconstructing) everyone else's decision perspectives to reach an agreement [146]. This process has its intellectual roots in the social construction of reality concept proposed by sociologists to explain how humans come to an agreement on issues [159]. Sociologists advocate that agreements, as social constructs, are always "observer-relative" and dependent on one's perspective toward the particular situation at hand. They also suggest that 
human perspectives are always adaptive and changeable due to dynamic social interactions with others - a concept that should be exploited by collaborative engineering research.

\subsubsection{Dynamic nature of stakeholder perspectives}

Next, we have observed that stakeholders' dynamically evolving perspectives during the coconstruction process are the critical connection between social interactions and technical decisions in an engineering team. During a collaborative engineering process, social interactions in teamwork alter stakeholders' perspectives toward the tasks at hand, which, in turn, influence their decision preferences in task-work. If properly managed, diverging preferences can be reduced to enable rational joint decisions to support team agreements [160]. The evolving decision perspectives occurring in these dynamic cycles lead to the important "underdetermined" features of collaborative engineering outcomes. In fact, we have noticed that an important challenge for an effective collaborative engineering team is to ensure that these social interactions are strategically guided so that stakeholders' dissimilar perspectives can evolve systemically toward a common understanding of the taskwork that results in a win-win outcome at the end.

\subsubsection{Collective innovation by engineering teams}

The last feature is that the most valuable result of a collaborative engineering exercise is not just simple deal-making to reach an agreement; the outcome also should include the possibility of collective innovation by stakeholders [23]. This is to say that the desirable results from a collaborative engineering team should go beyond task-work agreements that meet stakeholders' competing interests and requirements [161]. Whenever possible, the results should comprise an expansive set of alternatives (or new option spaces) from which previously unknown solutions or new innovations, which are impossible to obtain individually, can be created collectively. This suggests that, in addition to conflict resolution to achieve joint decisions, collaborative engineering research also should study the basic questions of collectivity via mutual knowledge probing (e.g., jointly exploring understanding and application of knowledge) and shared value creation (e.g., developing a common problem definition, value proposition, and solution formation) in teamwork. Such a construction type of teaming activities calls for the Participative Joint Decision task, as explained next.

\section{Review of Current Research Approaches}

Collaboration is a pervasive activity in modern societies and, as such, the literature on this subject can be found in a wide range of disciplines, including philosophy, psychology, sociology, economics, organization, decision, management, IT, and engineering. Since it is impractical to have a comprehensive assessment of such a broad subject, we will limit our literature review to representative studies that address the most important issues of collaborative engineering in industry. In this section, we evaluate some current approaches according to their disciplinary and application foci. The technology-oriented approaches (Section 3.1) focus on developing IT tools to support engineering collaboration of taskwork. The social science-oriented approaches (Section 3.2) aim at understanding the human aspects of collaboration and interactions in teamwork. The socio-technical-oriented 
approaches (Section 3.3) attempt to adapt social science understandings to enrich technological developments to support team collaboration. Because the collaborative engineering research framework described in this paper is mainly based on the negotiation viewpoint, we also include a brief review of this topic in Section 3.4. Section 3.5 presents CIRP's efforts that address the concerns of collaborative engineering. Section 3.6 summarizes the shortcomings of these present activities. We should point out that, intellectually speaking, the basic knowledge that underlies many of these approaches may not be "scientifically" new. Yet, their implications for production engineering have become increasingly important as development cycles are tightened to the minimum and product complexities are pushed to the maximum [33].

\subsection{Technology-oriented Approaches}

The technology-oriented approaches to collaborative engineering are mostly IT based [34]. In the IT research community, for example, database researchers study collaborative engineering as information management tasks, focusing on maintaining data integrity when changes are made by multiple stakeholders [35]. Computer-supported collaborative work (CSCW) scholars have developed some prescriptive guidelines and IT facilities for virtual teams [36], and human-computer interaction (HCI) researchers have addressed the "social blindness" problem when collective decisions are conducted in cyberspace [37]. Because conflict resolutions are the centerpiece of collective decisions, scientists have developed models and software tools that support the detection and resolution of conflicts in a variety of knowledge domains [38]. An example is the argumentation-based model developed by Toulmin [39], who promoted an informal but more robust approach in dealing with arguments than does traditional formal logic. Several argumentation-based conflict resolution methods and systems have been developed from this model [40]. Adoption of the argumentation model to support sociotechnical negotiations of software design is introduced in [41]. A review of an agent-based approach to collaborative design and manufacturing is in [42]. A comprehensive review and discussion of agent-based system for manufacturing is in [43]. An agent-based negotiation framework (ANF) for collaborative design is presented in [44]. Built on negotiation and multi-agent systems research, ANF comprises a negotiation protocol, a set of negotiation strategies, and a network of intelligent agents that help designers and computers to follow negotiation protocol, select negotiation strategies, and make proposals. Many of these IT-based studies are technology-centric, eschewing a deeper understanding of human behavior and social dynamics [45].

Many CAD/CAM tools have been developed to support the design process from the conceptual stage to final production [46]. In the past, most CAD/CAM systems were designed as standalone applications in an isolated environment [47]. Due to the widespread use of the Internet, some CAD/CAM tools have been extended to support distributed collaborative design over the Internet [48]. An example is the DOME system [49], which was built by integrating existing single-user CAD systems using web-based software technologies. These distributed CAD/CAM tools enable designers to share product models and other data from different sites [50]. However, because CAD systems use different native file formats, when multiple design teams use different CAD tools, consistency problems often arise [29]. This prevents design teams from sharing data outside the system [51]. Data 
communication is another problem that can occur when file transfers and data sharing go beyond the company's intranet. Security and authentication become major concerns when transferring project-critical files over the Internet. Future collaborative CAD/CAM tools need a common, secure communication infrastructure and protocol so that files can be transferred safely and shared accurately [52]. A few CAD tools have recently added some limited collaborative design capabilities for real-time communication, support for various CAD formats, and tools for manipulating models outside the original CAD programs [53]. An engineering process representation and modeling tool was developed for describing large-scale design processes involving tasks that are performed by automated computer agents in collaborative engineering [54]. Regardless, integrated collaborative design capabilities still cannot be fully realized by these distributed CAD/CAM systems. Other difficulties that need to be overcome include version control, data translation and repair, design process model, and many security and legitimacy issues [55].

A research system, STARS (Social-Technical Analysis Research System) [56], was developed to provide a Web-based environment that supports design process control, conflict management, and knowledge integration within the design team. Its objective is not to substitute the current CAD or MIS tools but rather to fill the gaps of collaboration supports. Stakeholders' perspectives are modeled in STARS, and their roles in task-work are depicted. Communication tools with networking and server-client database accessing functions support the stakeholders in declaring, sharing, and modifying their design prospective. Girod et al. [57] conducted an empirical study into how collaborative decision-making processes in conceptual design phase take place. Wang et al. [53] presented a comprehensive literature review of existing research projects dealing with collaborative engineering at the concept design stage. Both Web-based and agent-based collaborative conceptual design systems were surveyed. They identified potential areas for further research and development in this area, including system architecture for collaborative conceptual design, conceptual design modeling and data sharing, product-centric design method, concept selection, knowledge management in collaborative environments, distributed design project management, and development of virtual design studios.

\subsection{Social Science-oriented Approaches}

Although motivated by different practical needs and intellectual goals, many existing social science studies are applicable to the subject of collaborative engineering. The social science background knowledge that is most relevant to collaborative engineering research will be summarized in Sections 4.1 and 4.2. Here we will review two categories of social science research, communal communication and collective decisions, which are the hallmarks of collaborative engineering. Some social scientists have addressed group communication from the community point of view [58]. For example, social network researchers have theorized about information exchange (i.e., communication) in groups [59] as a cognitive behavior and social organizational issue [60]. Some theories for studying the flow and exchange of information in collaborative teamwork include transactive memory [61], social exchange, and public goods [62]. In these social science theories, much attention has been paid to people's abilities to work in communities [63] and to the consequences of such community-based actions. To identify the optimal mechanism for transferring information 
in collective actions, various configurations in teams' communication networks from both prescribed and emergent perspectives [64] have been studied. Other researchers have investigated the influence of knowledge network configurations on a team's effectiveness [65].

Making collective decisions via communal interactions to attain an agreement is key to collaborative engineering [66]. Various collective decision situations have been studied by analytical and mathematical approaches [67]. Optimization researchers model collective decisions as a multi-objective and multi-attribute optimization problem [22], wherein weighting factors are assigned, a priori, to rank stakeholder interests to compute a set of Pareto optimal outcomes [68]. This approach, although mathematically rigorous, requires prior knowledge about the problem and assumes that stakeholders' perspectives remain static during the collaboration process. It fails to deal with problems that are based on preferencedriven knowledge and require communal agreements. Some researchers have treated collective decisions as a multiplayer, interactive decision task and use game theory approaches to determine various equilibrium conditions and strategies [69]. While game theory models have sound mathematical bases, they lack direct relevance to engineering practices due to the strong requirement of prespecified payoff functions and the assumed static and rational nature of human perspectives.

Many empirical studies of collective decisions also can be found. For example, management researchers have studied collective decisions from a project management perspective, with practical guidelines and strategies to improve teaming effectiveness [70]. These researchers have focused on three fundamental problems with group decision-making, namely the impact of initial preference and time pressure, the impact of group dynamics and politics, and the lack of an objective quantitative group preference. They concluded that group decision-making is not effective unless there are objective criteria (e.g., money, time) that allow members to explicitly evaluate their decision choices [71]. Short of these objective criteria, group decision-making is recommended only for option generation (i.e., brainstorming) or other open-ended tasks of an exploratory nature. One study concerned the influence of group cohesion and information sharing on the effectiveness of design review [72] and found that the two factors that can negatively affect group collaborative decisions are high levels of group cohesion and group politics. The combination of high levels of group cohesion and considerable pressure to reach a decision is classified as "groupthink" [73]. An example of the impact of groupthink is the 1986 space shuttle Challenger disaster due to failure of the O-rings [74]. Despite strong evidence that serious safety concerns were present, NASA allowed a launch [75]. Overall, these approaches often treat human collaboration and technical decision issues in isolation, and the methodology is largely empirical, lacking a strong theoretical foundation.

\subsection{Socio-technical-oriented Approaches}

Because collaborative engineering entails both teamwork within a social system and taskwork within a technical system, socio-technical systems theory is a useful approach for studying this subject. Some initial efforts in technology management studies already have started to explore this direction [5]. Socio-technical research claims that considerations of social and technical subsystems within an organization must be optimized jointly and simultaneously for the greatest performances [76]. For the social subsystem, team members, 
their interactions, communication, and relationships with one another and the broader organization all play important roles [77]. For the technical subsystem, the technologies, procedures, and methods used by an organization should all be considered [78]. Sociotechnical research proposes that the levels of technology and task complexity have a large impact on group performance. Task characteristics, such as scope, structurability, and uncertainty, will affect the degree of complexity associated with any collaboration task [79]. The types of interactions utilized by teams, including criticisms, opinions, clarifications, and summaries, are key to the effectiveness of collaboration. Changes in the normal social subsystem, resulting in a narrower or less open exchange of ideas or information, will inhibit and hinder the success of design teams.

In the case of virtual teams, social subsystems already have enjoyed some improvement through advances in the technical subsystem [80]. Additional advancements in technology, such as those reviewed in Section 2.2, which support effective interactions between team members, can serve to reduce the social complexity. Although these technologies can enable more teams to simultaneously manipulate and discuss shared design representations, technological systems alone cannot provide an answer to the complexity problem presented by virtual teams. A review by Carey and Kacmar [81] has found that the introduction of technical systems brings about operational and behavioral changes, but not the desired increases in quality or productivity. Some current technologies appear to further complicate the distributed environment in most applications. Carey and Kacmar stated that using such technologies in an information-rich environment may be a poor choice. Their findings suggested rethinking the design of current collaborative technologies to ensure greater effectiveness. King and Majchrzak [82] analyzed the design of current tools and the underlying human factor assumptions in regard to how virtual groups successfully perform their work.

\subsection{Collaborative Negotiation Approaches}

Negotiation is a vital activity in collaborative engineering to reach agreements during the communal interaction and collective decision processes [83]. Many important tasks in production engineering involve negotiations [84]. For example, Quality Function Deployment (QFD) is a well-known method in industry for translating customer needs (voices) into design and production requirements during product development cycles. Traditionally, this method asks individuals to express their preferences in a restricted scale without much interaction with other stakeholders. Recent QFD exercises have placed more emphasis on having stakeholders collaborate and negotiate their joint preferences during focused group studies. Some recent research has extended the QFD method to account for stakeholders' multiple preferences and fuse them into one uniform group decision by means of fuzzy set theory [85]. Another example is [86], who observed that the key to developing complex systems lies in negotiating different perspectives such that a highly integrated and comprehensive result is achieved. A methodology is proposed that explicitly incorporates the multiplicity and diversity of perspectives encountered when designing these systems, which consist of many interfacing parts and different requirements regarding such con- 
cerns as performance, manufacturability, and economics. Collaborative negotiation is often used to justify and manage arguments caused by stakeholders' different preference, knowledge imprecision, or problem uncertainty in these systems engineering activities [87].

Although negotiation is a common activity in engineering practice, the subject has not been studied rigorously in the engineering research until recently [88],[89]. Adelson [90] applied a theory-based framework of collaborative negotiation to those disputes that regularly arise during design. A collaborative negotiation tool, NegotiationLens, was developed to resolve conflicts within and between engineering groups working on the Integrated Work Set project. To date, the most comprehensive effort to study collaborative negotiation in the engineering community is CIRP's Engineering Collaboration via Negotiation (ECN) initiative [16]. ECN studies "collaborative negotiation for engineering," with the goal of helping engineers to integrate their social and physical realities when making collective decisions in a highly dynamic socio-technical environment [91]. The six characteristics that delineate engineering negotiation problems are: (1) there are two or more parties involved; (2) there is a conflict of interest or resources between two or more parties; (3) the parties think that they can influence others to get more desirable outcomes; (4) the parties are willing to "give and take"; (5) the parties prefer to search for agreements outside of the "system" in order to avoid open fights; and (6) the parties are able to manage the "intangibles" to resolve the "tangibles" (i.e., "win-win" solutions are possible). Lu [92] developed five premises (i.e., basic assumptions) to guide ECN research: (1) one should negotiate when things are still "soft," i.e., negotiation support is most effective at early stages of engineering tasks [93]; (2) one should first seek to suffice before optimizing, i.e., a team should negotiate acceptable solutions before selecting the best from among them; (3) one should "interact" rather than "iterate," i.e., bi-directional reasoning methods are needed in negotiation; (4) one should always leave some rooms for others, i.e., interval/set representations are better than single point specifications; and (5) one should always prepare for later "regrets," i.e., keeping track of previous decision rationales for later use [94]. These ECN principles have been applied to early stage parametric design of mechanical systems [95]. More ECN research results are described in this paper.

\subsection{Related CIRP Efforts and Initiatives}

Before the ECN-WG started to focus on collaborative engineering research, the CIRP community already had a rich history of research in human-centered engineering subjects and many of its past efforts and current initiatives share a common concern with collaborative engineering. For example, many research efforts in CIRP's Scientific and Technical Committees, describing negotiation, concurrency, adaptation, customization, constraint-directed reasoning, complexity, optimization, and integration of production systems, are relevant to the constructivist approaches needed by collaborative engineering research. These projects typically employ some negotiation and collaboration, although without explicitly naming them, resulting in information exchanges that enable decision makers to give and take to arrive at positive outcomes for all parties. Due to the complexity of production systems, these negotiation strategies do not dwell on codified relationships; instead, they often work "outside the system" to reduce conflict and manage intangibles so that tangible solutions are achieved [96]. 
Before describing related CIRP research efforts, it is instructive to review a few projects that address similar problems without using negotiation or collaboration approaches. For example, optimization and validation are often accomplished via simulation [97], without negotiation. Similarly, adaptive control for many different manufacturing processes [98] can be accomplished by addressing strictly tangible parameters. Enforcement of design and geometry constraints can be accomplished with deterministic algorithms when the parameter space is stable [99]. Even probabilistic analysis and synthesis [100] can be conducted efficiently without negotiation.

Going forward, there are many results from CIRP research that contribute to collaborative engineering research. From an historical standpoint, pioneering efforts in defining the lifecycle concept by Alting and Jorgensen [101], engineering environments by Kimura et al. [102], and information technology infrastructures for engineering by Krause and Kind [103] all describe the requirement and motivation for collaborative engineering research. Joint decisions and collective actions are enabled by approach and tool that allow engineers to merge concepts. Shared dynamics entities, proposed by Noël and Tichkiewitch [104] for design systems, allow design models to be created and adapted within a continuously negotiated context. Concurrent engineering representations by Lindberg and Sohlenius [105] allow for a formal definition of information for quantitative measures of concurrency. Refinement methodologies, developed by Reddy and Lu [106], allow for the efficient refinement and optimization of designs, while considering multiple perspectives. Further, integration mechanisms addressing economic aspects [107], environmental effects [108], supply chain adaptation [109], multiple views of the product life cycle [110], collaborative aids [111], and process planning [112] are examples of CIRP research that address concept merging.

Moving between tangibles and intangibles in negotiation often requires redefinition of either design requirements or manufacturing capabilities. Co-evolution of conceptual design based on multiple functional considerations was explored in [113]. Design tools that balance assembly and disassembly requirements are described by Molloy et al. [114]. Multiple rule bases are used by Domazet et al. [115] to influence early stage design decisions according to different manufacturing perspectives. Wilhelm and Lu [116] developed a design synthesis approach that allows design requirements and fabrication strategies to be traded off via a parametric negotiation. Further efforts in distributed design [117], [118], [119], process planning [120], and life cycle goals [121] all support negotiation of tangible and intangible design requirements. Similar approaches also were developed for manufacturing planning and control. Elbestowi et al. [122] defined AI techniques to resolve and redefine competing force, path, and quality objectives. Westkämper \& Warnecke [123] developed knowledge-based learning systems to infer and redefine relationships between defects and drivers in single-product and series production. Blumfield et al. [124] defined adaptive CAM systems that reflect the manufacturing philosophy of individual users.

Customer-driven requirements and mass customization, described in a number of CIRP studies, explicitly call for the co-construction process of collaborative engineering. Jiao and Tseng [125] and Chen and Tseng [126] defined co-construction methods from customer and manufacturer perspectives. Similar techniques have been developed for design systems [127] and information management [128]. Many engineering tasks are underspecified and allow for multiple solutions that are useful as negotiating positions. Markus et al. [129] 
developed a constraint-based process planning system that yields a Pareto-optimal set of solutions. Krause and Golm [130] devised a general approach for multi-criteria process optimization that supports restructuring and investigation of multiple solutions. Dynamically evolving perspectives and collective innovation are requisites for the self-organizing systems designed for manufacturing control. Ueda et al. proposed biological manufacturing systems that adapt to diverse production demands and malfunctions [131], as well as autonomously generating facility layout plans [132]. The random manufacturing system proposed by Iwata et al. [133] adaptively generates manufacturing schedules, while contending with dynamically changing orders. The autonomous building blocks, defined by Sluga et al. [134], provide another approach for self-organized scheduling. Ueda et al. [135] describe how emergent synthesis approaches also can be used to realize self-organization.

Joint decision tasks are studied using fuzzy computation. Eversheim and Hack [136] addressed differing logistical goals, process flexibility, and schedule changes due to rush orders or disturbances within a multiple product, variant environment. Nota la Diega [137] accomplished similar results while coupling quantitative process performance with qualitative system goals. Liu et al. [138] described how distributed design efforts can be managed by balancing design metrics within a framework for uncertainty management. Coconstruction is the explicit mechanism used by Wilhelm et al. [139] for order and delivery negotiation in an e-commerce supply chain. The initial goals for order delivery are negotiated and reformulated as required via a constraint-satisfaction process. Each negotiation step is handled by means of the largest scope possible to avoid local sub-optimality. This global approach is then balanced with time constraints that apply in e-commerce supply chain execution. Kjellberg et al. [140] has developed different methods and computer tools to facilitate a common, in-depth understanding of the design problem at hand, the possible solutions, and their consequences. To support human-to-human communication and negotiation, they have developed a prototype of a 3D stereo interaction table that makes it possible for a group to sit around and interact with the digital model on the table and with each other. There is no need for special glasses, and everyone can see the same 3D model directly and notice each other's reactions with eye contacts.

Finally, system complexities have been studied using methods which are relevant to collaborative engineering. Schuh and Eversheim [141] used a time-wise bounding of component changes to maintain market diversity while driving down system complexity. ElMaraghy et al. [142] described a coding system that uses the probability of manufacturing system success to manage complexity of production requirements and configurations. Kjellberg [96] considered the complexity of production engineering problems to be negotiated. In her study, negotiations dealt with the extent to which multidisciplinary aspects should be treated, which is a negotiation in itself.

In addition to these individual research efforts by CIRP members, there are also broader initiatives in the CIRP community that address production engineering issues that share the goals of collaborative engineering. For example, the Human Factor and Education Working Group (HFE-WG) has discussed many human-centered approaches to engineering research and education, many of which are essential to the success of collaborative engineering. The Lifecycle Engineering initiative has investigated various ways to integrate multiple 
competing lifecycle concerns of the product, for which collaborative engineering approaches can play an important role. More recently, the Virtual Research Laboratory initiative, which aims to develop networks of excellence among multiple organizations, has presented opportunity to demonstrate and apply collaborative engineering approaches. Finally, the Manufacturing Paradigm initiative, which assesses the future of production industry, has outlined many technical and organizational challenges for which more advanced collaborative engineering capabilities are needed.

\subsection{What Is Missing from the Current Approaches?}

The technology-oriented approaches, although offering some functional tools, are often not grounded in the theoretical bases that underlie our understanding of the nature of human behavior and social dynamics. Existing analytical-empirical approaches often are not applicable to the practice of collaboration, while prescriptive IT tools seldom are formal enough to guide the collaborative process. While social science research provides some theoretical explanations of human and social dynamics, they often lack rigorously validated empirical studies of real-world tasks. As well, although this line of social science research has proven fruitful in its own right, it has largely neglected the intricacies of the technical decision-making tasks found in collaborative engineering.

In short, current approaches are, by and large, isolated from each other, narrowly focused in their own disciplinary scope, and insufficient for practical purposes. What is missing in current collaborative engineering research are theoretically guided studies that can systematically bridge the gaps between these separate schools of research in various social and natural sciences [143]. Broader interdisciplinary efforts are needed to advance this human-centered engineering subject, so that it can turn into a scientifically understood and effectively practiced discipline. The collaborative engineering foundation presented in this paper offers such a possibility.

\section{Background, Definitions, and Concepts of Collaborative Engineering Research}

This section provides the necessary background, definition, and key concepts for readers to begin to understand collaborative engineering studies. We should start with an examination of the characteristics of different collective human endeavors to delineate the correct meaning of "collaboration" in the context of human activities [144].

\subsection{Types of Collective Human Endeavors}

Humans must engage in collective endeavors to survive and succeed. According to cultural and historical activity (CHAT) theory [145], a foundation of psychological research, collective human endeavors occur at three related but distinctive levels: coordination, cooperation, and collaboration. Understanding these similarities and differences will enable us to study human collaboration and collaborative engineering correctly [146].

\subsubsection{Coordination}

At the most basic level, coordination is the regulation of diverse elements or activities into an integrated and harmonious operation. It links different parts to accomplish a collective 
set of tasks. Coordination occurs in many activities, such as biological systems (e.g., handeye coordination in sports), organizational affairs (e.g., project management in companies), business operations (e.g., logistics supply chains), and systems engineering (e.g., integrating multiple sub-systems). A clear example of a coordination activity is driving on a busy highway during rush hour-drivers in different cars, with different destinations and competing interests, must carefully "coordinate" with each other to avoid accidents that would delay traffic and harm everyone's interest. In many real-world situations, a predetermined structure (e.g., a hierarchy) is used to facilitate "coordination" among multiple activities. With a hierarchical structure, some scholars have defined "coordination" as the process of managing "unidirectional" task dependencies between activities "across multiple levels."

\subsubsection{Cooperation}

The next collective human endeavor is cooperation. It refers to the practice of people (or greater entities) working in common with shared resources and methods, instead of working alone or competitively. Although cooperation is seen as the antithesis of competition, the need to more effectively compete motivates individuals to organize into a group to cooperate. This is because there is always a trade-off between the efficiency of obtaining a desired resource and the amount of resources that one can actively obtain alone. Therefore, it is often a good idea for individuals in a group to focus on producing a specific resource and then to obtain other resources by trading. A "cooperation by trade" model with bidirectional dependencies is established. In the previous example of highway driving, a driver may focus on the driving task, while a passenger helps with road navigation. Their cooperation brings benefit to both parties, enabling them to safely arrive at a destination on time. Repeated interactions and relationships, such as those seen in engineering teams, are important in promoting cooperative behaviors in organizations. Further, when a hierarchical task structure is provided, "cooperation" can be defined as the process of managing the "bidirectional" task dependencies between activities "within the same level" of the hierarchy.

\subsubsection{Collaboration}

The highest level of collective human behavior is collaboration. In the dictionary definition, collaboration $(\mathrm{co}+$ labor + ation $)$ refers abstractly to all processes wherein people work together. On the surface, this definition looks similar to that of coordination and cooperation (hence the common misunderstandings). However, collaboration has more stringent requirements than does the other two. For example, while coordination avoids gaps or overlaps in individuals' assigned tasks, and cooperation strives for mutual benefits by sharing or partitioning tasks, collaboration aims at achieving a common goal and collective results that individuals would be incapable of accomplishing alone. In other words, collaboration requires a team of individuals to work on tasks that not only have shared resources (as in coordination) and shared outcomes (as in cooperation), but, most importantly, a shared common goal.

Due to the knowledge complexities and/or resource limitations, tasks that require collaboration are impossible for individuals to pursue separately. Because no one can succeed 
alone and all participants are important, individual latitude and commitment in collaboration are substantially higher than is seen in coordination or cooperation. At the same time, the complexities, dependencies, and dynamic nature of collaboration tasks call for the stakeholders to have a higher degree of autonomy and more direct participation to benefit from the true synergy of teamwork. In fact, synergy among individuals is the biggest benefit of collaboration, which should not be bound by a given task hierarchy. Recall that both coordination and cooperation deal with cases in which some task structures are known and given. Collaboration, in contrast, must face the most difficult situation in which these task dependencies and hierarchical levels are not fully defined a priori and, hence, must be dynamically constructed by participating stakeholders during collaboration. In fact, the ability to innovatively construct these "relationships" (or task hierarchies) is important for successful collaboration.

Having explained the characteristics of collective human endeavors in terms of the stakeholders, resource, goals, and structure, we should point out that in many real-life situations, stakeholders must engage in all types of endeavors dynamically and amorphously. This reflects human's ability to cope with changing social or technical settings of collective actions. For example, a team of stakeholders may start with a coordination task that calls for cooperative efforts, which, in turn, leads to deeper collaboration, and vice versa. It is therefore important to assess each collective human action carefully in terms of the characteristics of its stakeholders, resources, goals, and structure to understand the appropriate endeavor. Table 2 summarizes these distinguishing characteristics to guide such assessments [147].

\begin{tabular}{|c|c|c|c|c|}
\hline & Stakeholder & Resource & Goal & Task Structure \\
\hline Coordination & Large community & $\begin{array}{l}\text { Limited and } \\
\text { exchanged }\end{array}$ & $\begin{array}{c}\text { Multiple and } \\
\text { competing }\end{array}$ & $\begin{array}{l}\text { Predefined, same } \\
\text { layer in hierarchy, } \\
\text { unidirection }\end{array}$ \\
\hline Cooperation & Midsize group & Limited and shared & Multiple and private & $\begin{array}{l}\text { Predefined, across } \\
\text { layers of hierarchy, } \\
\text { bidirection }\end{array}$ \\
\hline Collaboration & Small team & $\begin{array}{l}\text { Limited, shared, } \\
\text { complementary }\end{array}$ & Single and common & $\begin{array}{l}\text { Undefined, } \\
\text { nonhierarchical, } \\
\text { multidirection }\end{array}$ \\
\hline
\end{tabular}

\subsection{Constituting Disciplines of Human Collaboration}

With the advent of the Internet, research into the properties, processes, and mechanisms of collaborative human endeavors has intensified, and more light is being shed on this ubiquitous and taken-for-granted human practice. The resulting new knowledge can help scientists to predict the "hard bounds" of collaborative behaviors, provide "short proofs" of collaborative results, and offer "simple models" of collaborative processes [148]. Additionally, this body of knowledge can serve as a rigorous scientific foundation to support collaborative engineering research, making it much easier and more closely aligned with 
the path used to pursue traditional science-based engineering subjects. Unfortunately, despite intensive studies, we still do not have clearly defined and well-accepted "sciences of collaboration" to directly launch collaborative engineering research. Nevertheless, scholars in this emerging scientific field have suggested that "future" collaboration sciences could evolve from synthesizing the interdisciplinary research of a few relevant disciplines, of which the most important ones are organizational science, social cognition, social choice, and decision science. The knowledge and concepts learned from these fields can be synthesized and integrated to establish collaboration sciences and, in turn, to support collaborative engineering research in the future. Some background knowledge and basic concepts of these contributing disciplines of human collaboration are presented below.

\subsubsection{Organizational science research}

Organizational science uses the combined knowledge of economics, sociology, political science, anthropology, and psychology to investigate individual and group dynamics in an organizational setting as well as the nature of organizations themselves [65]. When people interact in organizations, different factors than those found in open groups in society come into play. Organizational studies attempt to understand and model these factors, such as the concepts of "bounded rationality" and "sufficing" (in contrast to the concepts of "absolute rationality" and "optimizing" from neoclassical economics) [149]. Indeed, the need for an organizational theory resides in the fact that there are always practical limits to human rationality and available resources, and that these limits are not static but rather depend on the specific organizational environment in which the individual interacts. One of the goals of organizational science is to enable individuals, when they engage in collaborative activities within organizations, to approach rationality as closely as possible in their decisions and actions.

Organizational science holds that stakeholders always engage in collaborative endeavors as members of a purposeful "team." Different from a group, a team consists of a distinguishable set of members who dynamically interact toward a set of common and valued goals, who have each been assigned a specific role or function to perform, and who have a limited life-space of team membership [62]. Organizational science suggests that, in collaborative teamwork, separate and selective incentives must be provided to stimulate rational individuals to act collaboratively in a team-oriented manner. This provides an adequate foundation to understand and manage the social interaction of engineering teams because they always operate in corporate environments that have established incentives. Members must be carefully selected so as to bring complementary expertise to the collaborative engineering team as well strategically assigned to different functions with clearly understood responsibilities [150]. With such systematic organization, all team members will work collaboratively toward the team goal, rather than selfishly based on their separate interests. Organizational science is becoming more important in the global economy, as people with

diverse backgrounds and cultural values must work together effectively, a goal shared with collaborative engineering. 


\subsubsection{Social cognition research}

Social cognition is a part of psychological research that deals with "self-conceptions" and what the individual perceives to be within his or her horizon of actions [151]. Specifically, it investigates how individuals perceive, influence, and relate to others by studying the relationship between minds and behaviors in groups. Based on the premise that "minds can be shaped by others," social cognition research has long proven that individuals' perspectives change their preferences, which guide their decisions. In social cognition, a perspective is defined as a set of values (e.g., experiences, beliefs) that shape the way an individual perceives reality and responds to it. These studies also confirm that individuals' perspectives are not static but are always dynamically evolving when they interact with others in social settings. In teamwork, specifically, research has revealed that individuals often participate in a mutual, reciprocal, and dynamical social construction process, whereby each "constructs" others' perspectives (e.g., understandings, interpretations). Unlike organizational science or sociology studies, which focuses on the structure and organization of groups without focusing on individuals' minds, social cognition looks at the "inside" to understand how individual minds change in the context of social interactions.

First, social cognition research attempts to understand and explain how the thoughts, feelings, decisions, and behaviors of individuals are influenced by the actual, imagined, or implied presence of others. The relevant concepts include social perception, social interaction, and many kinds of social influences (e.g., trust, power, persuasion). Second, such research tries to understand the influence that individual perceptions and behaviors have on the behavior of groups. This includes concerns such as group productivity in the workplace and collective decision-making. Finally, it tries to understand groups as behavioral entities as well as the influence that one group has on another group's preferences. That group preferences should be expressed with respect to a common understanding, established via dynamic social interactions, is the centerpiece of our constructivist approach to collaborative engineering research. We must understand the dynamics and processes of change in stakeholder perspectives to enable more systematic social interactions in collaborative engineering practice. After all, if human minds remained unchanged regardless of their social presence and interactions, collaboration science (and collaborative engineering) would not have been an interesting and worthwhile field of study beyond the traditional decision sciences.

\subsubsection{Social choice research}

Social choice is a branch of social science that studies how individual preferences can be logically aggregated to form a consistent group preference for collective decision-making [152]. This is an important requirement in many applications, including, for example, macroeconomics, democratic voting, and collaborative engineering. One of the most wellknown studies in social choice research is Arrow's possibility theorem [153], which states that "no social preference function can satisfy the four criteria (i.e., unrestricted domain, Pareto Efficiency, independence from irrelevant alternatives, and non-dictatorship) of democratic decision-making in groups simultaneously". Because this theorem suggests that there is no procedure for combining individual rankings that can lead to a consistent group ranking, some have insisted on a rigid position that "group decision-making by all 
is not rational, never consistent, and inherently chaotic" [10] (hence, Arrow's impossibility theorem). If this theorem is true under all conditions, then group decision problems, which depend on finding a good group preference, become theoretically impossible and all group decision practices are then unavoidably ad hoc and eventually chaotic [6]. However, we must understand that Arrow's impossibility theorem is based on the discrete social-choice model that ranks a set of discrete preferences, which is different from the spatial socialchoice model that is based on a rating of continuous sets of alternatives. Recent social choice research has discovered that, instead of additive aggregations of individual preferences as rankings of discrete alternatives, members can explicitly compare and negotiate their interpersonal preferences, using ratings of continuous alternatives, to construct a group preference rationally [154]. The same also has been proven by decision scientists analytically, who have used preference ratings, not rankings, to derive a group preference that can satisfy Arrow's four criteria of democratic decision-making [155]. Nevertheless, social choice research to date has been largely based on the assumption that individuals' preferences remain static, regardless of their social interactions (i.e., disregarding the research in social cognition described in Section 4.2.2).

\subsubsection{Decision science research}

Decision science is an interdisciplinary field, incorporating knowledge from mathematics, statistics, economics, philosophy, psychology, management, and engineering [156]. It studies how analytically-inclined individuals (should) make rational decisions and how "optimal" decisions can be reached. Most decision theory to date is either normative or prescriptive and is mainly concerned with identifying the best decision, assuming an "ideal" decision maker who is fully informed, given unlimited resources, and can reason with perfect accuracy and full rationality (i.e., contradicting the organizational science concepts, Section 4.2.1). Because it is clear that people do not behave in such optimal ways, there are also descriptive studies in decision science that attempt to understand what real people actually do in various decision-making situations. The practical application of decision science research is called decision analysis, which tries to find practical methodologies and tools to help real people make better decisions. Most classical decision analysis has followed an "alternative-focused" approach, while some "modern" research has been based on a new "value-focused" thinking [157]. The word "modern" is used here purposely to differentiate it from the classical normative decision science, which is strictly based on the expected utility theory. There also have been many studies on how multiple individuals make decisions interactively, represented by game theory research [12] and negotiation analysis [158], which provide fundamental knowledge for collaboration sciences and collaborative engineering. Game theory focuses on finding winning strategies for interacting but separate decision-making, whereas negotiation is studied as means to resolve conflicts or settle disputes among interacting parties. For example, negotiation analysis research has combined analytical techniques from classical decision analysis, behavioral decision theory, and game theory to support groups of reasonably rational individuals in making single, joint, collaborative decisions. Both competitive (or win-loss) and cooperative (or winwin) negotiations have been studied extensively by decision scientists. However, when applying this decision science research to practice, many of its assumptions, such as perfect 
information, unlimited resources, full rationality, and a static perspective must be relaxed to account for the complex dynamics of group decisions under the influence of social interactions (i.e., including social cognition studies, see Section 4.2.3).

Each of the above disciplines addresses some limited aspects of group interactions and decisions, but they all fall short of attending to the complete scope of human collective actions in organizations [150]. For example, organizational science provides useful insights into how stakeholders should be organized for productive social interactions, but it does not deal with the evolving perspectives that result from these interactions. Social cognition focuses on changing minds and perspectives but does not specifically concern itself with how these changes could affect individuals' decisions. Social choice research investigates how multiple preferences should be aggregated, with the assumption that stakeholder preferences are static (i.e., ignore social interactions). Decision science has studied different decision-making scenarios in which stakeholders have competing preferences, despite the fact that their preferences can be altered during social interactions. Nevertheless, if we put these separate disciplines together under a logical framework, they can collectively constitute a body of transdisciplinary knowledge that can explain how humans interact and collaborate with each other in organizations. This body of knowledge also can provide a useful theoretical basis for collaboration sciences, upon which a scientific foundation of collaborative engineering can be established.

\subsection{A Formal Definition of Collaborative Engineering}

In practice, collaborative engineering occurs whenever a team of stakeholders engages in collaborative endeavor (Section 4.1) to attain a consensual agreement for complex tasks in organization. Unfortunately, as an emerging practice, collaborative engineering has come to mean "many things to many people." To some, it conjures up sophisticated technologybased communication with remote colleagues, while to others, it means agreeing to work together on some common engineering efforts. A practical definition of collaborative engineering was given in [18], which breaks it into two components: collaboration and engineering. "Collaboration" means any effort to collaborate to exchange information, ideas, or useful resources necessary to create a shared understanding for a common and creative purpose. "Engineering" refers to projects that primarily involve some technology-intensive efforts, such as new product development activities that require a host of engineering disciplines. Combining the two, collaborative engineering becomes the collaborative exchange of resources among a team of stakeholders focused on a technology-intensive project with some overall common and creative purposes. This definition has its merits, but is somewhat vague and hence insufficient to support rigorous scientific studies of the subject. In our research, we have adapted a more formal definition of collaborative engineering as a new sociotechnical engineering discipline, which:

facilitates the communal establishment of technical agreements among a team of interdisciplinary stakeholders, who work jointly toward a common goal with limited resources or conflicting interests 
According to this definition, collaborative engineering is a human-centered socio-technical activity, consisting of a dynamic co-construction process to maximize the synergy between the technical task-work by individuals and the social teamwork by groups [44]. Unlike traditional science-based engineering studies that are mostly concerned with individual decisions based on "brute reality" (i.e., observer-independent phenomena according to the science of the natural), collaborative engineering also must deal with team agreements based on "social reality" (i.e., observer-dependent opinions according to the science of the artificial) [159]. While we can study traditional engineering as a technical decision process (i.e., "task-work") by individuals, collaborative engineering must additionally be considered a social endeavor of "teamwork" to reach consensual agreements among multiple stakeholders [56]. To collaborate effectively, stakeholders must work as "teams" in organizations, rather than acting as "work groups" in open communities. As stated in Section 4.1, the main difference is that a team must share resources and outcomes to achieve a common goal via collaboration, whereas a group may share resources for individual gain through coordination or cooperation. From a scientific viewpoint, one should also note that simultaneous engineering and collaborative engineering address practically related but intellectually different problems in production engineering [3]. The former is concerned with the scheduling of multiple task-works to minimize the lead-time (i.e., coordination or cooperation within groups), whereas the latter focuses on the synergy between task-work by individuals and teamwork by groups (i.e., collaboration in teams).

A complete collaborative engineering study should include both joint decisions and collective actions by engineering teams. Because we can assume that teams will always take collective action based on their joint decisions (and, according to the cooperative game definition, a collaborative engineering team should have the ability and authority to enforce its joint decisions), our research has been mainly focused on the joint decision aspect of collaborative engineering. Because joint decisions entail multiple stakeholders working collaboratively in a sociotechnical setting to reach agreements, its underlying mechanism is different from that when separate decisions are made by individuals. For example, when deciding on a technical issue in solo work, a stakeholder can theoretically choose from all available options based on his or her own preference to rationally maximize utilities and minimize risks. His or her decision "preference" is a personal concern and is assumed to be known, a priori. This situation fits well with the scope of a classic rational decision scenario, which presumes that individuals are always self-interested, with full rationality and unlimited resources. The traditional approach supposes that a stakeholder's decision "perspective" (i.e., how one views the world and the problem at hand, which is the root of one's decision preference) always remains static and is unaffected by social interactions that take place when working with others in a community. That is, it neglects the fact that social interactions during teamwork can dynamically influence individuals' perspectives, which, in turn, alter their preferences in making joint decisions. In short, the traditional approach misses the great opportunity of "changing minds" in social settings and the benefit of "two heads are better than one," which is the rationale underlying collaborative engineering [162]. 


\subsection{The Participative Joint Decision (PJD) Task}

While traditional engineering studies "decision making by individuals," collaborative engineering must focus on "agreements by teams" via joint decisions. In practice, stakeholders can engage in group decision-making in different ways, ranging from one extreme of a strong supra-leader in a dictatorship team to the other extreme of a leaderless setting in a democratic team. For the former, traditional decision analyses provide simplified solutions, whereas for the latter, an open brainstorming approach offers some limited guidance. However, we have observed in engineering practice that both of these extreme styles are ineffective in terms of their productivity and innovation. Most importantly, they fail to realize the full potential of collaborative engineering.

Additionally, we believe that the biggest challenge that a collaborative engineering team faces is when task-work, due to its complexity and diversity, requires participation by, and active contributions from, all stakeholders. In this case, especially when task structures are unknown or not predefined, nothing short of truly joint decisions, which are agreed upon and committed to by all, will suffice in reaching a team agreement. Another challenge is when the collaborative engineering team is assigned to open-ended task-work that calls for creative thinking and innovative input from everyone to produce and explore new options that are beyond the past experience and knowledge of any one member. Contributions from all are important to this construction type of collaboration task (Section 4.4.5). Based on our observations, we conclude that when faced with these challenges, a collaborative engineering team cannot function effectively with either the dictator or leaderless style. Instead, the team must adapt a "guided-democratic" style, allowing each member to play a more proactive and fully participative role in making joint decisions so that everyone will have a say and an ultimate stake in the final team agreement.

We refer to this "guided-democratic" decision task in teamwork as a "Participative Joint Decision" (PJD), which is essential for reaching team agreements [163]. PJD is a systematically steered and managed group decision style, in which all stakeholders jointly participate in and fully collaborate on making joint decisions to agree on task-work. To achieve PJD, a team must establish a consistent group preference "by all" and "for all" stakeholders during the social interaction process. We believe that PJD is the most challenging aspect of teamwork and the biggest benefit of collaborative engineering. Hence our research has mainly focused on PJD as an important approach to attain team agreement in collaborative engineering. Section 5 will explain how we delineate PJD scientifically.

\section{The ECN Research Hypothesis}

A research hypothesis is a contention that has yet been neither proven nor ruled out. According to the "Observation $\rightarrow$ Hypotheses $\rightarrow$ Theory" development pathway of our scientific foundation, we need to put forth a research hypothesis suitable for the developments of a collaborative engineering theory. This hypothesis must be based on human collaboration knowledge and well informed by the observations of successful collaborative engineering practices. The Engineering Collaboration via Negotiation (ECN) concept is the research hypothesis developed by the CIRP/ECN-WG. ECN hypothesizes how engineers in a collaborative engineering team can (and should) best accomplish a PJD task with other 
interested stakeholders in order to reach consensual agreements on technical assignments. The ECN research hypothesis is formally stated as follows:

Engineering Collaboration via Negotiation (ECN) is a guided teamwork process which a collaborative engineering team can employ to achieve a task-work agreement. The ECN teamwork process uses an "Interaction $\rightarrow$ Perspective $\rightarrow$ Preference $\rightarrow$ Agreement" mechanism to attain Participative Joint Decisions that underline the task-work assignments.

The ECN hypothesis advocates that stakeholders in a collaborative engineering team should employ a dynamic, socio-technical co-construction process, to collaborate with each other reciprocally to reach PJDs on task-work matters, including, for example, resolving disagreements or conflicts, bargaining for individual or collective advantages, agreeing on courses of action, or crafting joint decisions that serve their mutual interests. It offers an appropriate viewpoint toward the nature of engineering tasks when they are performed by multiple stakeholders in a team setting. Table 3 compares the different views between the traditional engineering and ECN.

\begin{tabular}{ll}
\multicolumn{2}{l}{ Table 3. Compare traditional engineering and ECN views } \\
\hline Traditional Engineering Viewpoints & New ECN Viewpoints \\
\hline Based on Sciences of the Nature & Based on Sciences of the Nature and Artificial \\
Purely technical considerations & Socio-technical considerations \\
Seek correct and optimal answers & Obtain satisfying and rational consensuses \\
Focus on consistent maintenances & Focus on conflict resolutions \\
Application of deterministic knowledge & Co-construction of collective agreements \\
\hline
\end{tabular}

\subsection{The Basic Mechanism of the ECN Hypothesis}

The means for making a PJD that is asserted in the ECN hypothesis is "Interaction $\rightarrow$ Perspective $\rightarrow$ Understanding $\rightarrow$ Preference $\rightarrow$ Agreement." This basic mechanism is derived from the studies of human collaboration knowledge and observations of high-performance engineering teams. It outlines how a PJD task can be systematically carried out by participating stakeholders to achieve agreements in collaborative engineering team [163].

1. Social interactions in teams can dynamically change participating stakeholders' perspectives toward a collaborative engineering endeavor and task-work.

2. Stakeholders' changing perspectives, when properly managed and guided, can lead to a common understanding of the task-work at hand by the team.

3. Such a common understanding serves as an anchor for stakeholders to discourse and compare their individual preferences to obtain a group preference.

4. The consistent group preference derived from a common understanding by the team can drive stakeholders' joint decisions to reach an agreement.

5. This task-work agreement influences future social interactions of stakeholders, leading to the dynamic socio-technical cycles of collaborative engineering. 
The constituting disciplines of human collaboration (see Section 4.2) provide some theoretical bases to support the above ECN basic mechanism. We should note that the word "social"" which has many meanings, refers specifically to the collaborative behaviors that take the interests of others into account in the ECN hypothesis. "Social" also captures those stakeholders' collaborative characteristics that influence team dynamics during social interactions, including the nontechnical aspects of stakeholders, such as their background, objectives, interests, and criteria. Initially, they are brought into the collaborative teamwork by participating stakeholders and then are dynamically coconstructed and continuously evolve throughout the social interaction process (see Section 5.3). Therefore, the term "socio-technical" in ECN signifies the mutual consideration of, and the true integration and synergy between, the social (teamwork) and technical (task-work) aspects of collaborative engineering. The ECN mechanism explicitly treats the PJD task as a dynamic interface between group interactions and individual decisions as well as an assimilation of social and technical activities operating in parallel over different time, space, and discipline boundaries in an engineering team. This ECN hypothesis serves as a "point of departure" for our collaborative engineering research described in this paper.

\subsection{A ECN-based Collaborative Engineering Process}

The basic mechanism asserted in the ECN hypothesis leads to a new collaborative engineering process for PJD to address the challenges of collaborative engineering practice (Section 2.3). This new process (Figure 4) hinges on a basic ECN assertion that, "social interaction alters stakeholder perspectives that lead to a common understanding, which defines individual preferences that underlie team agreement."

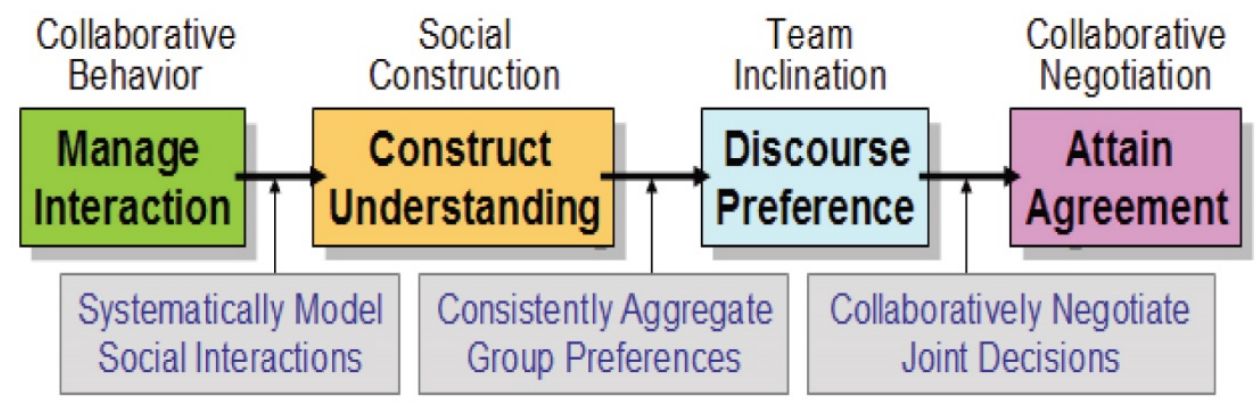

Figure 4. ECN-based collaborative engineering process

\subsubsection{Manage social interaction}

This initial stage is based on the ECN mechanism that "social interactions can dynamically change stakeholders' perspectives of a collaborative engineering endeavor." The collaborative behaviors of the engineering team are the core issue that must be carefully managed to assemble the team and guide its social interactions. At this preparatory stage, we select team members with complementary expertise (i.e., define the stakeholders), establish clear team goals and outcome expectations, clarify resources and constraints, and declare a baseline procedure (i.e., standard workflows) for team control so that all stakeholders are ready 
to engage in social interactions at the next stage. The understanding and management of stakeholders' collaborative behaviors is best achieved through organizational behavior theory (Sections 4.2.1 and 6.2.1).

\subsubsection{Construct common understanding}

The second stage is derived from the ECN mechanism that "stakeholders' changing perspectives, when properly managed and strategically guided, lead to a common understanding of the task-work at hand." The focus here is on guiding stakeholders to collaboratively co-construct each other's "perspectives" to obtain a common understanding of the task at hand (e.g., the real problem to be addressed). This dynamic co-construction process should be strategically guided, so that initial differences among stakeholders' diverse understandings of (and their competing preferences for) the task-work, reflected by dissimilar perspectives, can be calibrated, eliminated, or minimized as much as possible [164]. This can avoid unproductive interactions at later stages whereby stakeholders waste much effort in insisting on conflicting preferences caused by different expectations or misunderstandings of the task-work. To guide this coconstruction process, we must model and track stakeholders' evolving perspectives (e.g., changing interpretations of task-work) during social interactions to account for flexible interpretations when establishing a common understanding. Social cognition knowledge (Section 4.2.2) and social construction theory (Section 6.5.2) provide some useful models for this stage.

\subsubsection{Discourse group preference}

In the next stage, according to the ECN mechanism, "the common understanding obtained above serves as an anchor for stakeholders to discourse and compare their individual preferences fairly to obtain a group preference." Here, after the co-construction of a common understanding, stakeholders discourse their "remaining" dissimilar preferences to collaboratively establish a group preference for joint decisions. The common understanding of the task-work is used as a reference point for all stakeholders to consistently and fairly express their dissimilar preferences toward the issue at hand. Appropriate numerical simulation models, based on the domain knowledge of the task-work, can be used to generate a continuous set of alternatives and rate (not rank) stakeholders' preferences for different alternatives. These spatial social-choice models (Section 4.2.3 and 6.2.3) capture the "relative strengths" of individual stakeholders' preferences expressed against the socially constructed common task-work understanding at Stage 2. Then, interpersonal comparisons of preference strengths can be carried out via negotiations in the next stage.

\subsubsection{Attain team agreement}

The last stage, based on the ECN mechanism, is that "a consistent group preference derived from a common understanding of the task-work can be used to drive stakeholders' joint decisions in reaching a team agreement collaboratively." Given a consolidated group preference established by the team in the above stages, stakeholders can now directly participate in collaborative negotiations to compare their preferences and make joint decisions that lead to a robust team agreement for the task-work at hand. Due to the carefully orga- 
nized team membership and well managed social interactions in Stage 1, the socially coconstructed common task-work understanding in Stage 2, and the consistently established group preference in Stage 3, the collaborative negotiation activities at this stage can be systematically supported and guided by negotiation analysis techniques from the decision sciences (Sections 4.2.4 and 6.5.4). This completes the ECN-based collaborative engineering process, resulting in a PJD and agreement for all, and by all, stakeholders in a collaborative engineering team.

\subsection{Achieving Rationality during an ECN Process}

According to classical decision theory (Section 4.2.4), a rational decision can be made only when a clear goal and an unambiguous preference system are available. This requirement should hold true for both individual and collective decisions [165]. Given the fact that social interactions can change stakeholders' perspectives and preferences dynamically, how can this requirement be met so that the outcome (i.e., agreement) from an ECN-based collaborative engineering process can be as "rational" as possible? This question is the most important criterion for evaluating any collaborative engineering processes.

Before answering this question, we must clarify a common misunderstanding between the concepts of rationality and optimality, which are familiar terms to engineers. According to the classical rational choice theory, a rational decision body should always choose what they "believe" to be the "best" (or the most optimal) option to achieve the given objective. The notions of "believe" and "best" in this theory lead to the common confusion between optimality and rationality. First, we must understand that a belief is a human cognitive state in social reality (Section 4.3) which is observer-dependent; a belief may or may not be logically true in the context of brute reality which is observer-independent. One can only rationalize but not optimize a human belief in decision making. Second, the so-called "best" option can be determined only in the context of rational human belief in real-world decisions. Under bounded rationality (Section 4.2.1), an "absolute best" (or a strict optimality), even it can be theoretically obtained via optimization under the pure brute reality assumption, is often unknown or unachievable. Therefore, in real-world decision making, optimality is not the same as rationality, and vice versus. Only in highly idealized cases, which never occur in collaborative engineering practice, can these two concepts become isomorphic.

In Section 4.3, we define collaborative engineering as the synergy between teamwork and task-work. Teamwork guides stakeholders to attain collective rationality, based on which global optimality of task-work can be attempted. Again, collective rationality in teamwork should not be confused with global optimality in task-work. The latter should be grounded in the former, but the reverse is not true. To explain how our ECN-based process can guide stakeholders to attain collective rationality, Figure 5 graphically illustrates the concepts of decision goal, objectives, and preferences under the dynamic influences of social interactions and evolving perspectives. 


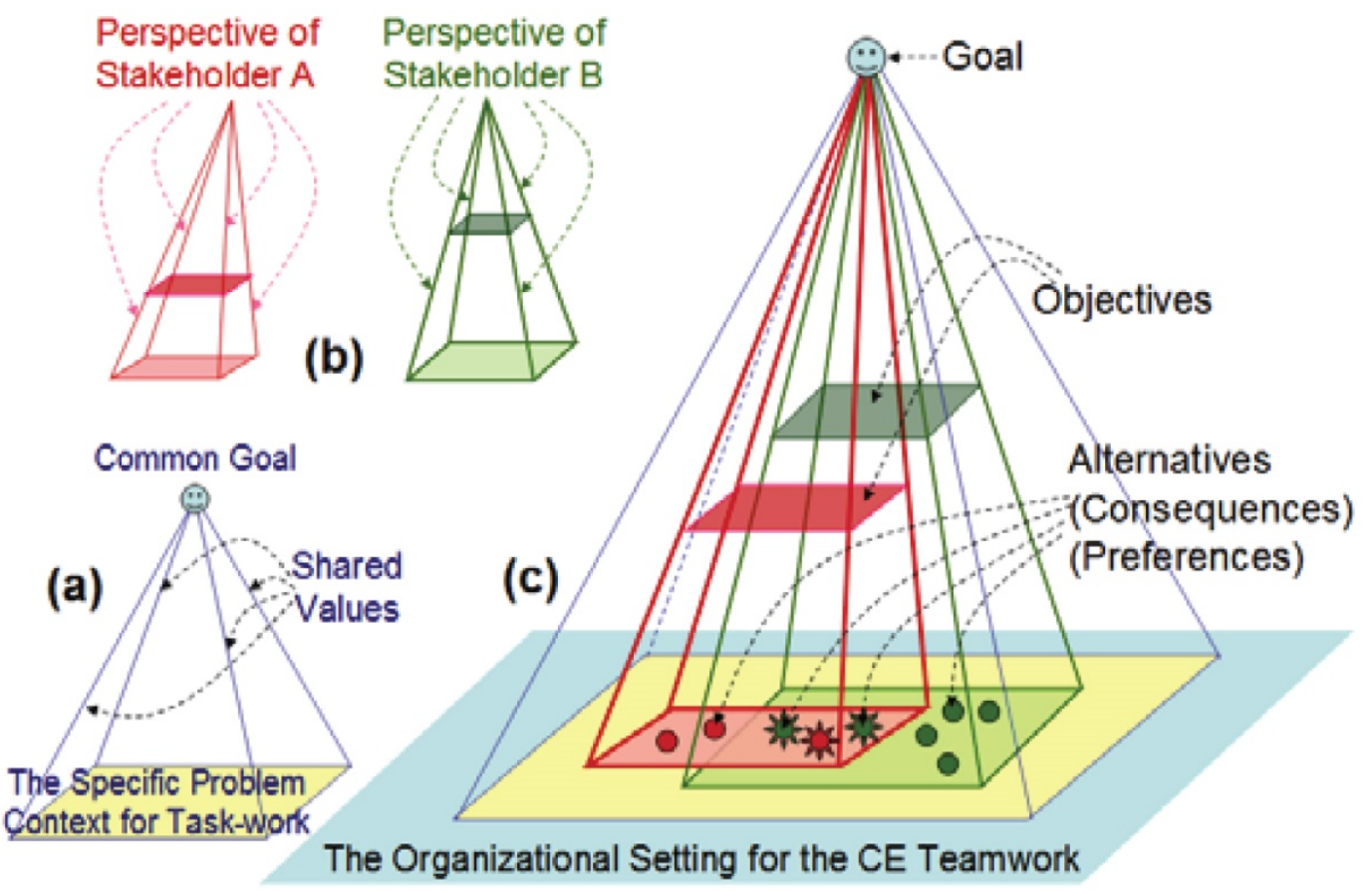

Figure 5. Social interactions in collaborative engineering

We follow the "value-focused thinking" approach that uses shared "values" to "frame" a specific problem context for the given assignment [159]. We assume that collaborative engineering teams perform their assignments within an organizational setting such that their social interactions can be properly directed based on corporate incentives. This gives the "strategic context" for the teamwork and is conceptually illustrated by the light blue plane of Figure 5(c). We also assume that members of the collaborative engineering team have already agreed on a common goal and shared a set of values, based on which the team determines a specific problem context for the assignment within the above "strategic context." Together with the common goal and the teamwork strategic context, these shared values result in a constrained volume shown as the blue-lined pyramid in Figure 5(a). This closed space defines the "boundaries" (i.e., the problem frame) within which stakeholders engage in social interactions as they collaborate on the assignment (Stage 1 in Section 5.2.1).

With a common goal and shared values, each member brings a different "perspective," based on his or her expertise, background, interests, and objectives into this problem frame. As defined in Section 4.1, a perspective captures the particular way (or viewpoint) from which a shareholder perceives the problem at hand. Operationally speaking, a stakeholder's perspective can be conceptually represented as his/her unique "projection" of the common goal onto the specific problem context for the assignment within the problem frame (i.e., the blue-lined pyramid), established above. This is graphically illustrated by smaller pyramids in Figure 5(b), which show two different shareholders' perspectives (i.e., red- and green-colored projections). Metaphorically speaking, this is like "shining a spotlight onto a dark stage," and the locations of the projections of the spotlights can be 
changed by the stage manager's perspective. Figure 5(c) shows how the two stakeholders can bring their perspectives (i.e., different spotlights) to the problem context of the assignment (i.e., the blue-lined pyramid, or the dark stage). Figure 5(c) also indicates that although stakeholders must commit to a common goal and share a set of values, they can initially have different objectives and alternatives (based on their unique knowledge about the consequences of alternatives and their preferences derived from previous experiences) resulting from their different perspectives.

Stage 2 (Section 5.2.2) then prescribes a process for the two stakeholders to dynamically co-construct each other's different perspectives, via guided social interactions (within the blue pyramid), to achieve a common understanding of the assignment. Conceptually, this common understanding represents the collective rationality among stakeholders toward the assignment. Graphically, this is analogous to moving the initial projection locations of the two spotlights on the dark stage so that the overlapping area becomes as large as possible. In our ECN-based process, the evolving stakeholder perspectives due to social interactions are equivalent to a continuous shifting of spotlight projection locations. During this dynamic process, stakeholders' perspectives are continuously changed, which, in turn, alters their decision preferences and alternatives. Because alternatives that lie within the overlapping area of the spotlights are based on a common understanding (i.e., overlapping perspectives with collective rationality) of the assignment, they are the best candidates for stakeholders to attain PJDs and negotiate a team agreement.

Moving to Stage 3 (Section 5.2.3), stakeholders can now discourse their individual preferences against these alternatives, based on their common understanding and collective rationality (e.g., the three star shapes in Figure 5(c)). Because individual preferences are now "grounded" in a socially constructed common understanding (or collective rationality) of the assignment, aggregation of multiple preferences to establish a group preference for a collective decision become possible and more rational. Based on this consistent group preference, stakeholders can collaboratively negotiate joint decisions to arrive at a sound agreement that approaches global optimality, as indicated by Stage 4 (Section 5.2.4). This completes the ECN-based collaborative engineering process that meets the criteria of having clear goal and consistent preference of rational decision making.

\section{A Socio-Technical Framework (STF) for Collaborative Engineering}

The last step in our "Observation $\rightarrow$ Hypothesis $\rightarrow$ Theory" development pathway is to put forward some preliminary theories for collaborative engineering based on the ECN hypothesis (Section 5.1) as a means to embrace the ECN process (Section 5.2). The theory layer of our scientific foundation begins with a "conceptual framework" derived from our theoretical knowledge and practice observations. In research, a framework refers to "an abstract model" of the domain under investigation. A framework is proposed, with an underlying hypothesis by researchers, based on their current best understanding of and insights into an emerging subject, to serve as a beginning step in developing a domain theory. Typically, a framework for an emerging discipline should include a defined theoretical architecture with some prescribed means by which implementation can be organized and applications can be executed. After continuous validation and refinements, a 
framework can gradually evolve to become an initial theory that, with further developments, can steadily advance to a more formal theory. Building upon the ECN hypothesis and process, we have developed a Socio-Technical Framework (STF) for collaborative engineering. The followings are important insights that underlie this STF theoretical framework:

- Constructivist is a more appropriate approach (than is deterministic philosophy) to study the dynamic, socio-technical, and underdetermined nature, and to support the task-work and teamwork integration.

- Social interaction must be managed systematically so that a common understanding of the task-work can be first established by the team collaboratively for members to express their individual preferences.

- Co-construction operation during social interactions should be strategically guided so that the initial disparities between stakeholders' perspectives can be calibrated and abridged as much as possible.

- Team preference can be consistently established if expressed against a common understanding and compared by ratings of continuous alternatives using spatial socialchoice models.

- Joint decision can be rationally attained to reach a team agreement if stakeholders are systematically guided through the collaborative negotiation process based on the above consistent group preference.

\subsection{Architecture of the Socio-Technical Framework}

Based on the ECN hypothesis, STF explicitly addresses the social interaction of engineering teams and models the dynamic nature of the PJD task. Traditionally, an engineering task is treated as a technical process, consisting of a series of iterative decision-making (or mapping) operations between the "WHAT" (i.e., what do you wish to achieve?) and the "HOW" (i.e., how do you propose to achieve it?). Other questions, such as "WHO" (e.g., who are the stakeholders of this decision?) and "WHY" (e.g., what are the stakeholder rationales?) that are essential for collaborative engineering are left out as separate management functions. Integration of technical decisions and social interactions in teamwork is the chief challenge that our STF is designed to address. Figure 6 conceptually shows the two-dimensional architecture of the proposed STF, in which technical decisions (i.e., individual task-work) are represented as the "WHAT $\rightarrow$ HOW" mapping along the $\mathrm{X}$-axis, and social interactions of engineering teams (i.e., group teamwork) are shown as the "WHO $\rightarrow$ WHY" mapping along the Y-axis. 


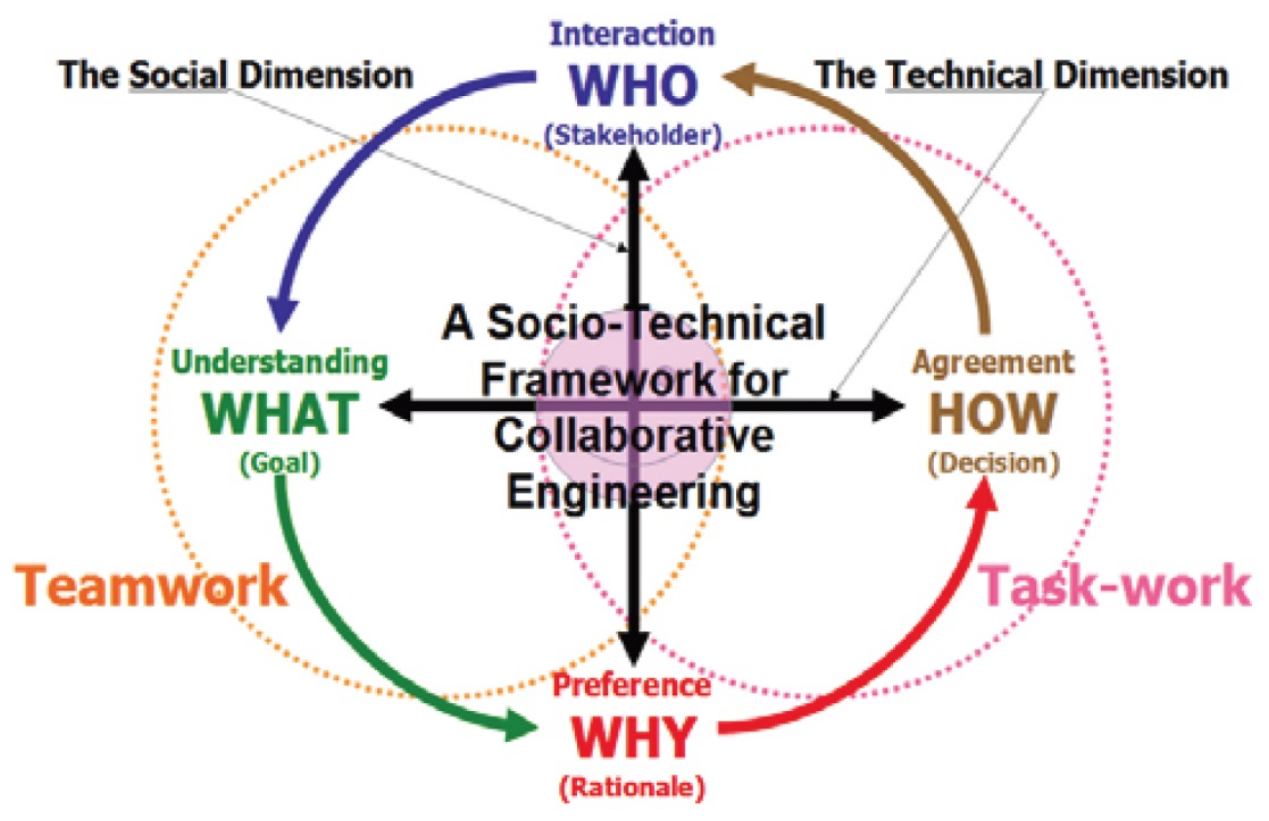

Figure 6. Architecture of the socio-technical framework

Rather than treating teamwork and task-work separately and sequentially, the STF synergizes social interactions and technical decisions to form an integrated cycle, reflecting the four stages of the ECN-based collaborative engineering process (Section 5.2), that guides a collaborative engineering campaign for stakeholders to reach team agreements [166]. As shown in Figure 9, a typical collaborative engineering campaign is initiated by organizing a team of participating stakeholders (i.e., WHO). The actual endeavor starts from the topleft quadrant, with the "WHO $\rightarrow$ WHAT" mapping that represents the social interaction (Stage 1 of the ECN process) among participating stakeholders, whose decision perspectives on the said technical issue will continuously evolve. Next, the collaborative engineering team proceeds to the bottom-left quadrant (i.e., the "WHAT $\rightarrow$ WHY" mapping) to socially construct a common understanding (Stage 2 of the ECN process) of the said technical issue. Anchored in this is shared understanding of the task-work, the "WHY $\rightarrow$ HOW" mapping (i.e., the bottom-right quadrant), which then establishes a consistent group preference or a team inclination (Stage 3 of the ECN process) for all participating stakeholders to make joint decisions. Finally, the collaborative engineering campaign arrives at the bottom-right quadrant, where joint decisions, supporting a team agreement (Stage 4 of the ECN process), are systematically negotiated according to the above agreed-upon group preference. This team agreement will, in turn, affect the future social interactions of participating stakeholders on the next or other team projects, leading to the dynamic socio-technical cycles that continuously establish and refine the "team norms" and "corporate culture" in engineering organizations [167].

Due to the dynamic social interactions that take place at the upswing of this STF cycle, the final outcome of a collaborative engineering campaign is intrinsically different from 
that of traditional approaches. Contrary to the usual deterministic philosophy, the collaborative engineering results, according to the constructivist thinking of the STF, are sufficiently "underdetermined" to account for the possibility of multiple interpretations by stakeholders and engineering teams (Section 6.5.2). In other words, whatever joint decisions were finally agreed upon by a particular collaborative engineering team could have been different with a different team with different stakeholders at a different time under a different social context. It is important to note that an "underdetermined" system is not necessarily a chaotic one that is unmanageable. To administer this "under-determinism," one must take a constructivist, rather than a determinist, approach in order to focus on the "systematic process" rather than the "specific result" of the system. We believe that this "underdeterminism" feature, resulting from evolving stakeholder perspectives during social interactions, is a fruitful opportunity, rather than a hindrance, in collaborative engineering. It should be explored to promote collective innovation and creativity (Section 4.4.5) by engineering teams to realize the true benefits of collaborative engineering practice. This is the reason that we have chosen to investigate the proper procedure, not the exact predictability, in our collaborative engineering research.

\subsection{Models and Techniques to Instantiate the STF}

There are three capabilities (Figure 7) that are required to instantiate the above STF so that we can validate the ECN hypothesis. To provide for these required capabilities, each of the four stages of the ECN collaborative engineering process (Section 5.2) must be attended to by some appropriate theoretical models and practical techniques derived from the relevant knowledge of the constituting disciplines of collaboration sciences (Section 4.2). Some suggestions for research to develop these needed models and techniques to support PJD are presented below.

\subsubsection{Understand collaborative behaviors to manage social interaction}

We suggest using organizational behavior theory from organizational science to model stakeholders' social interactions and collaborative behaviors as an "organizational man" working in a "small and induced" team, rather than treating them as an economic man operating in a large open group [62]. This theory states that there are always practical limits to stakeholders' rationality (hence the bounded rationality concept) in teams and that these limits are not static, but rather they depend on the dynamic social and organizational environments within which stakeholders' decisions take place (Section 4.2.1). Whereas a classic economic man on the open market tries to optimize (i.e., selects the best alternative from among all), an organizational man in a team seeks to satisfy (i.e., looks for agreements that are satisfactory or "good enough" for all) [168]. The difference between an optimal decision and a satisfying agreement is fundamental to collaborative engineering research. A decision is optimal if there is a set of criteria that permits "all" alternatives to be compared and the alternative in question is preferred by these criteria to "all" other alternatives. In comparison, an agreement is satisfactory if there is a set of criteria that describes minimally satisfactory alternatives and the alternative in question "meets or exceeds" all these criteria. These "satisfying" and "bounded rationality" concepts from organizational behavior 
theory underlie our approach to managing stakeholders' collaborative behaviors in engineering teams, in that a joint decision in teamwork is always exercised with respect to limited resources and represents an approximate model of the actual situation. In such a case, these elements are not given or static but are the outcome of dynamic sociological processes, including the stakeholders' own and others' decisions in a collaborative engineering team.

\subsubsection{Employ social constructions to create common understanding}

It is important to elucidate the mechanism by which a common understanding of the taskwork at hand can be systematically established by all stakeholders via social interactions. Without such a process to iron out the diverse interpretations first, individual stakeholders could end up insisting on their conflicting preferences, caused by incompatible interpretation or different understanding of the same task, hindering the establishment of a team inclination for joint decisions at the next stage. Based on social cognition knowledge (Section 4.2.2), we propose to use social construction theory to understand how social interactions in teams can be systematically guided to lead to a common understanding in teamwork. In social science, social constructions, or social constructs, are the result of human choices (i.e., social realities, as opposed to brute realities based on the laws of nature). In recent studies, this concept has been expanded to refer to "the process of socially shaping an agreement or artifact by interested stakeholders," which makes it applicable to modeling the collaborative teamwork activities in collaborative engineering. A social construction process has four key features [169], which are all important to collaborative engineering:

Interpretive flexibility. This relativistic idea suggests that making a collaborative decision with social interactions is actually an open process, which can produce different outcomes depending on the particular set of stakeholders and social circumstances of its development. For example, researchers have applied this interpretive flexibility concept to explain how new technological artifacts are the result of human negotiations and agreements based on different and changing perspectives. Since collaborative engineering involves social interactions, its outcomes are "social constructs" that are always "underdetermined" to reflect flexible and multiple interpretations by members of different teams under different social circumstances. Such under-determined processes, although hard to manage, can be properly guided via social constructions, so that they will not result in chaos in the real world.

Relevant social group (RSG). Members of an RSG share interpretations (i.e., same perspectives) of task-work. Social interaction in collaborative engineering becomes an iterative process in which all RSGs, each embodying a specific perspective of a said technical issue, engage in discourse of its different interpretations, with other RSGs constructing different opinions based on their perspectives. This dynamic co-construction process continues until the discourse brings all stakeholders to a consensus that their resulting common interpretations work satisfactorily for all. That is, social constructions in a collaborative engineering process ceases not because the team interpretation works in some objective 
and absolutely optimal sense according to laws of the nature but because all involved stakeholders agree and accept that it works for them at that particular time.

Closure and stabilization. The above discourse process often results in controversies when different RSGs' interpretations lead to conflicting opinions (or decisions) of the same task. This process must continue until such conflicts are resolved (or at least result in a cessation of further conflicts) and the resulting interpretation no longer poses a problem to any stakeholder. When the collaborative engineering process achieves "closure" via collaborative negotiation or conflict resolution, no further arguments will occur and the shared interpretation and perspective stabilize to form a common understanding of the task-work. Such a stable state, which is particular to the said collaborative engineering team at the time, becomes the starting point for the next round of social constructions as the task-work, team, or time evolves, leading to the interesting socio-technical cycles of collaborative engineering in modern enterprises.

Wider context. Recent social construction studies have recognized that there is always a wider socio-cultural-political milieu in which the social construction process takes place in real-world teams and organizations. We have observed in engineering teams that these "background conditions," e.g., members' relationships, professional expertise and past track-records, corporate operating procedures ordering the interactions, and perceived organizational powers, are all important to the process and result of collaborative engineering practice. In our research, these wider contexts and background information are incorporated as a way to circumvent Arrow's paradox (which is based on a democratic decision-making), when the team tries to form a consistent group preference (Section 6.2.3).

An implementation example of this social construction process is presented in Section 7.

\subsubsection{Discourse stakeholder inclinations to establish group preference}

The next fundamental technique is concerned with how a group preference can be established and used for a PJD task by a collaborative engineering team. The possibility of consistently aggregating the preferences of many into a single group preference is what makes the PJD task in collaborative engineering possible and challenging. This capability hinges on the opportunity for stakeholders to collaboratively engage in open discourse about and fair comparisons of their different preferences [170], based on a socially constructed common understanding (Section 6.2.2). Individual preferences and their relative strengths, expressed against this common understanding, must be represented and rated in a continuous option space with spatial social-choice models (Section 4.2.3). Unlike many applications, for which continuous alternatives are often either impractical or impossible due to the nature of domain knowledge and representations, engineers can often use proper numerical simulation models to generate real-numbered alternatives in a continuous space. We believe that, especially in the engineering domain, in which many physics-based models exist, preferences (and their relative strengths) for multiple task-work alternatives can be formulated and compared (via open discourse) using uni- or multi-dimensional spatial preference models with a continuous set of alternatives. This affords us the unique opportunity of establishing a group preference consistently to carry out the PJD task to achieve 
team agreement in collaborative engineering that does not violate Arrow's group decision theorem.

\subsubsection{Utilize joint negotiation to attain team agreement}

The last issue relates to how stakeholders can make joint decisions that lead to a robust team agreement based on the consistent group preference established by all members above (Section 6.2.3). After Arrow's group decision paradox is removed, stakeholders can directly and proactively participate in making joint decisions via collaborative negotiations based on the group preference derived from spatial social-choice models of the domain. This interactive process can be best understood and guided through knowledge of decision science (Section 4.2.4), especially negotiation analysis studies [158]. When multiple stakeholders make joint decisions to reach an agreement on a specific alternative, and they share the consequences or payoffs, they must collaboratively negotiate with each other for winwin solutions. Our ECN hypothesis expands the traditional notion of negotiation for competitive bargaining to depict collaborative negotiation as an effective means to accomplish the PJD task. To negotiate collaboratively, stakeholders must coconstruct a common understanding, shared perspectives, and reasonable preferences that result in a satisfying agreement for all, with improved utilities for, at least, some. Relevant concepts, such as the bounded rationality and satisfying concepts from organizational behavior theory, the social interaction and social construction from social cognition, and the rating of continuous alternatives from social choice (Section 4.2), must all be incorporated in the ECN-based collaborative negotiation approach.

For example, the "satisfying" concept in ECN resonates with the BATNA (best alternative to a negotiated agreement) principle from negotiation research [158]. Stakeholders must start with clearly identified BATNAs before engaging in collaborative negotiations because they cannot make a wise decision about whether to accept a negotiated agreement unless they know what their other alternatives are. If the proposed agreement is better than a BATNA, then stakeholders should accept it; otherwise, they should continue negotiations. The "bounded rationality" and social interaction concepts in ECN match well with the EATNA (estimated alternatives to a negotiated agreement) principle from negotiation research. Perceptions (e.g., perspectives of the task-work at hand) are what matter in a negotiation, when it comes to deciding whether to accept an agreement. If stakeholders "think" that they have better alternatives, they will often pursue those options, even if they may not be as good as they appear to be. If stakeholders "think" that others have better alternatives, they will often be more willing to agree to keep them in the negotiation. One of the ECN challenges is to be able to influence the other party's perception (i.e., decision perspectives) of your BATNA in the team's overall favor via guided social interactions (Section 6.2.2). This may require the FOTE (fully open and truthful exchange) principal from negotiation analysis being in place for all stakeholders involved in a collaborative engineering negotiation.

To complete the description of our scientific foundation of collaborative engineering, Table 4 summarizes the above required models and techniques as well as their respective disciplines that can instantiate the STF and the ECN-based collaborative engineering processes. We also contrast the existing approaches with that of collaborative engineering to 
indicate areas where new research efforts are needed. We should note that other disciplines, such as cybernetics [171], control theory [172], systems engineering [173], design theory and methodology [174], and network and information technology [102] can also contribute to the development of these needed models and techniques, but they are not discussed here.

\begin{tabular}{|c|c|c|c|c|}
\hline $\begin{array}{l}\text { ECN Collaborative } \\
\text { Engineering } \\
\text { Process and Stage }\end{array}$ & $\begin{array}{l}\text { Required } \\
\text { Models and } \\
\text { Techniques }\end{array}$ & $\begin{array}{l}\text { Constituting } \\
\text { Discipline }\end{array}$ & $\begin{array}{l}\text { Traditional } \\
\text { Approach }\end{array}$ & $\begin{array}{l}\text { Collaborative } \\
\text { Engineering } \\
\text { Approach }\end{array}$ \\
\hline $\begin{array}{l}\text { (1) Manage } \\
\text { interaction }\end{array}$ & $\begin{array}{l}\text { Collaborative } \\
\text { behavior }\end{array}$ & $\begin{array}{l}\text { Organizational } \\
\text { science }\end{array}$ & $\begin{array}{l}\text { Economic man } \\
\text { operates in open } \\
\text { large groups }\end{array}$ & $\begin{array}{l}\text { Organizational man } \\
\text { operates in small } \\
\text { teams with } \\
\text { incentives }\end{array}$ \\
\hline $\begin{array}{l}\text { (2) Construct } \\
\text { understanding }\end{array}$ & $\begin{array}{l}\text { Social } \\
\text { construction }\end{array}$ & $\begin{array}{l}\text { Social } \\
\text { psychology }\end{array}$ & $\begin{array}{l}\text { Self-interested full } \\
\text { rationality with } \\
\text { static perspective }\end{array}$ & $\begin{array}{l}\text { Social construction } \\
\text { theory with } \\
\text { dynamic evolving } \\
\text { perspective }\end{array}$ \\
\hline $\begin{array}{l}\text { (3) Discourse } \\
\text { preference }\end{array}$ & $\begin{array}{l}\text { Team } \\
\text { inclination }\end{array}$ & Social choice & $\begin{array}{l}\text { Ordinal ranking } \\
\text { with discrete social } \\
\text { choice models }\end{array}$ & $\begin{array}{l}\text { Cardinal rating } \\
\text { with spatial } \\
\text { continuous social } \\
\text { choice model }\end{array}$ \\
\hline $\begin{array}{l}\text { (4) Attach } \\
\text { agreement }\end{array}$ & $\begin{array}{l}\text { Collaborative } \\
\text { negotiation }\end{array}$ & $\begin{array}{l}\text { Decision } \\
\text { science }\end{array}$ & $\begin{array}{l}\text { Classic decision } \\
\text { analysis; game } \\
\text { theory approach }\end{array}$ & $\begin{array}{l}\text { Collaborative } \\
\text { win-win negotiation } \\
\text { framework and } \\
\text { analysis }\end{array}$ \\
\hline
\end{tabular}

\section{Modeling Stakeholder Perspectives during Social Interaction}

The "dynamic stakeholder perspectives" are the key linkage between the teamwork of groups and the task-work of individuals in our STF. This is because, for a team to carry out the PJD task collaboratively to reach an agreement, we must allow and, in fact, encourage the stakeholder's decision perspectives of (and preferences for) task-work to vary during social interactions. If these perspective and preference variations can be properly guided in teamwork, they can maximize the synergy among stakeholders, leading to task-work results that are beyond the reach of any single mind. Unfortunately, this dynamic feature makes the understanding and management of collaborative engineering activities very difficult. We believe that the ability to model the dynamic evolution of stakeholders' perspectives during teamwork to establish a common understanding of task-work is one of the most important challenges in our proposed STF. To demonstrate how such a modeling capability can be developed, this section presents an example implementation, called a SocioTechnical Co-construction Procedure (STCP), which can make the ECN-based collaborative engineering process operational [175]. Here, co-construction is a dynamic interaction process of gradual and mutual confluence of stakeholders' different perspectives via conflict management to collaboratively produce a shared reality (or a common understanding) 
that individuals are unlikely to produce on their own. The STCP explicitly models stakeholders' changing perspectives and tracks their dynamic perspective models as a way to resolve decision conflicts during collaborative negotiation to reach an agreement.

\subsection{The Socio-Technical Co-construction Procedure}

An STCP has three basic components working in sync to achieve a PJD. The first is "declare an initial task-work decision process," which serves as the baseline process of an STCP. The baseline process refers to a series of structured activities, consisting of tasks and states, which must be performed by stakeholders according to some preestablished task-work steps adapted from the specific domain practices or mandated by corporate policies (e.g., standard operation procedures). For example, when a collaborative product development team tries to identify the voices of customers from the market, the team may choose (or be required by their company) to follow the established QFD procedures as their task-work baseline process, from which an STCP is enacted. Tasks and states of this baseline process are required inputs for an STCP, acting as the "initial conditions" of a collaborative engineering campaign; they will be dynamically coconstructed during the campaign as a result of social interactions in teamwork.

The second component is "analyze stakeholders' perspective models." The human perspective is a complex phenomenon that is impossible to model in an all-encompassing manner. Therefore, we take a simplified approach to define a "perspective" as the stakeholders' current "viewpoint," which includes the purpose, the context, and the content, toward specific concepts in the concept structure of a task-work. A concept structure (CS) is an ontological organization of information about the task-work that stakeholders propose and use in a collaborative process. Our models focus only on those "pertinent perspectives," i.e., perspectives that are directly germane to the concepts of stakeholders' specific interests in the CS. This gives us the ability to analyze, track, and possibly eliminate the differences (or conceptual distances) among these pertinent perspective models as a means to manage the conflict among stakeholders at any given time (see the third component below). The results of these perspective model analyses can also provide explanations of stakeholder decisions and offer some rationales for future conflict management by the team. Although limited in scope, the perspective models in our STCP have rather complex behaviors because we treat stakeholder perspectives as evolving entities that are dynamically modified (or co-constructed) by other stakeholders during an STCP.

The third component is "manage stakeholders' conflicts," which are defined and quantified by the "conceptual distance" between stakeholder perspectives of a specific concept in the CS. Conflicts take a more positive role in our STF, serving as the "driving force" behind the synergy between teamwork and task-work. In an STCP, conflicts are revealed by perspective model analyses (see the second component above) and are resolved systematically with different strategies based on these analysis results. The earlier and more frequently that we can identify, manage, and resolve conflicts in teamwork, the better the collaborative engineering task-work outcomes will be. The team can collaboratively deal with conflicts by using the rich information captured and modeled in stakeholder perspective models. For example, aided by the purpose and context information (Section 6.2.2) in 
the stakeholders' perspective models, various social or technical conflicts can be managed and resolved at the content, context, or purpose level.

\subsection{Eight Specific Steps of an STCP}

An STCP can be realized by eight consecutive steps, which connect the conceptual propositions derived from the STF (Section 6.2) with operable actions based on the ECN-based collaborative engineering process (Section 5.3). We should note that these specific STCP steps represent just one possible means by which the PJD task can be realized and managed in collaborative engineering and that many other alternative approaches exist. Figure 7 illustrate these steps and how they operate together to reach a PJD based on the ECN hypothesis [166].

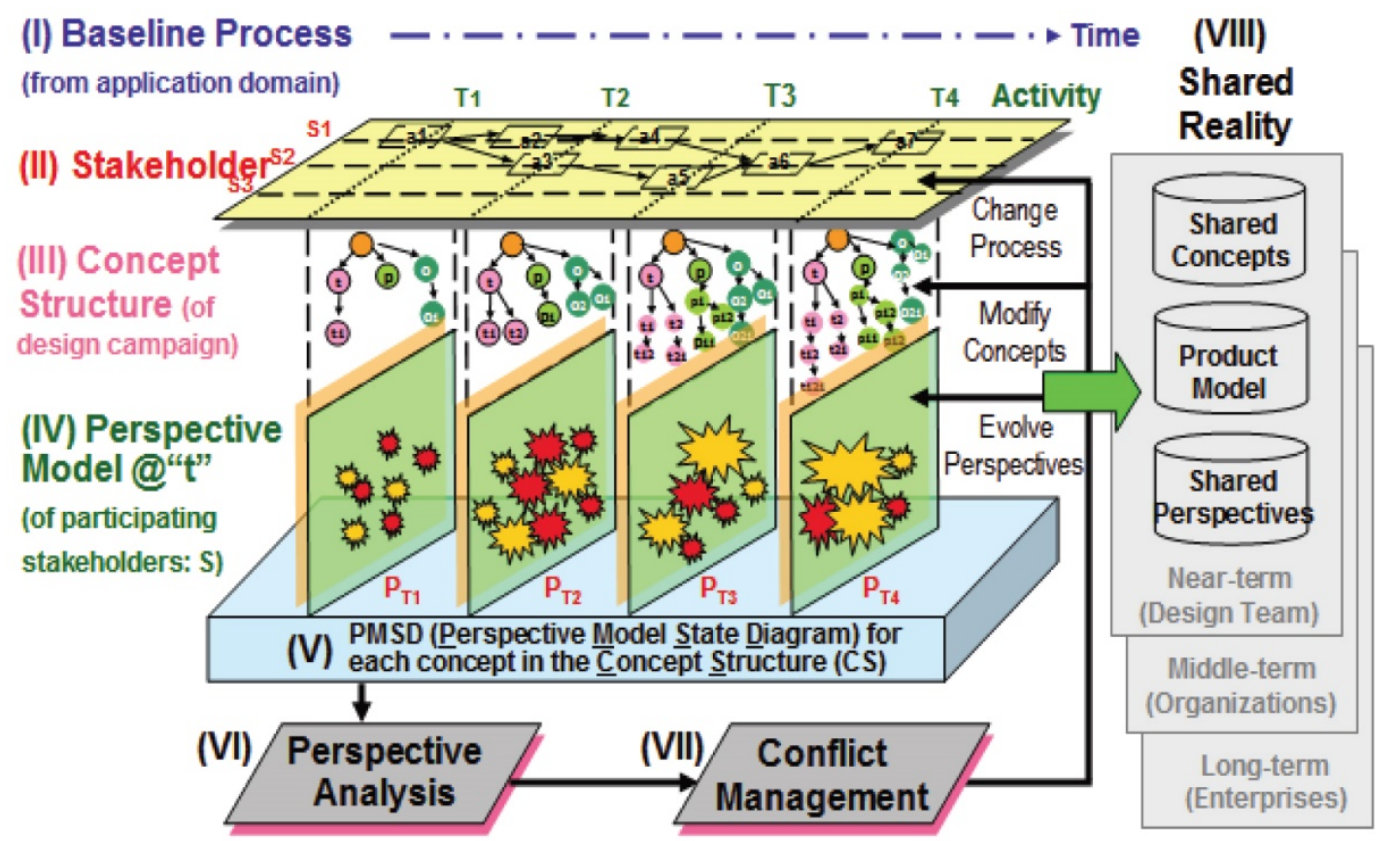

Figure 7. Eight specific steps of an STCP

Step 1. Define "Baseline Process" (BP) to initiate STCP:

The baseline process represents commonly accepted "workflows" of task-work from the technical application domain. These "workflows" specify the necessary technical steps that dynamically produce the "knowledge flows" throughout the STCP, based on social interactions among participating stakeholders (Step 2). The initial BP can be modified later as a means to resolve conflicts. 
Step 2. Identify "Stakeholders" (S) for an STCP:

Stakeholders are those who have an interest in the outcomes of, and will directly or indirectly participate in, an STCP. This definition extends the traditional scope of a collaborative engineering team beyond engineers to also include other nontechnical parties (e.g., customers and regulatory agents) as participants. Stakeholders play a key role in the STCP, proposing concepts to the CS (Step 3) and carrying out required tasks.

Step 3. Propose a preliminary "Concept Structure" (CS):

A CS is an "initial proposal" of required task-works suggested by stakeholders, based on their experiences, domain knowledge, or standard solutions. During the progression of the BP (Step 1), once an STCP begins, CS will be dynamically grown, revised, and continuously enhanced by all stakeholders. In this way, the initial CS will get progressively more complete as different concepts are added or modified by all stakeholders.

Step 4. Establish initial "Perspective Model" (PM) in CS:

Once a preliminary CS is proposed (Step 3), all stakeholders can express their current opinions towards specific concepts in the CS in which they have a direct interest or special expertise. These "opinions" are represented as the stakeholder's "perspective model" of those specific concepts at that time. During the STCP, these perspective models will be dynamically modified and thus evolve with time via social interactions.

Step 5: "Perspective Model State Diagrams" (PMSDs):

PMSDs explicitly depict the "relationships" among stakeholders' current own or shared perspectives, i.e., purpose, context, and content information in regard to a concept in the CS. They provide a structured way to systematically compare and examine the "perspective differences" (Step 6) among involved stakeholders as a means to guide the conflict management activity (Step 7) to achieve a common understanding and agreement.

Step 6. Perform the "Perspective Analysis" (PA):

The above PMSDs provide structured information, which can be periodically analyzed to reveal the distances between different stakeholder perspectives of a specific concept in the CS at given time intervals. To facilitate teamwork effectiveness, some predefined (or coconstructed) thresholds can be used to cluster different stakeholders as RSGs (Section 6.2.2), based on their perspective distances at that particular moment.

Step 7. Conduct "Conflict Management" (CM):

Based on the above PAs, stakeholders are in conflict if their perspective distances are larger than the preassigned thresholds (or belong to different RSGs). CM attempts to reduce these distances to reach consensual agreement among stakeholders by changing their perspectives, concepts in CS, or the baseline steps. After proper conflict resolution strategies are implemented, the STCP continues to iterate (from Step 4) until no further conflict is detected. 
Step 8. Obtain the "Shared Reality" (SR):

The final outcome of an STCP is called "shared reality" (i.e., common understanding or agreement). In addition to a product model (in the case of product development), SR may also include newly co-constructed domain concepts and shared stakeholders' perspectives, which are useful for future collaborations among same stakeholders on similar problems. More socially co-constructed SRs by collaborative engineering teams can improve an organization's competitiveness in the long run.

Various implementation options exist to make the above STCP steps operational, so that the STF and the ECN hypothesis can be validated. For example, methods such as colored Petri-nets can be used to model the baseline process (Step 1) that can drive an STCP and then, in turn, be driven by the conflict management activity. Further investigations on the proper architectures of concept structure (Step 3) are needed, so that it can serve as a central repository of task-work information and work synchronously with the Perspective Models (Step 4) of stakeholders. Next, we present an example implementation that uses a discrete-time dynamic system and feedback control engineering approach [176] to model the dynamic evolution of stakeholders' perspectives using PMSDs and PA (Steps 5 and 6).

\subsection{The Dynamics of Stakeholder Perspectives}

As an example, we present a discrete-time dynamic system and feedback control engineering approach to mathematically model the co-evolutions of stakeholder perspectives. After completing Steps 1, 2, 3, and 4 of an STCP (Section 7.2), we assume that each stakeholder $j$, at any instance of time $t$, has a store of internal information $\left(H_{j, t}\right)$, a perspective $\left(P_{j, t}\right)$, and the external data $\left(D_{j, t}\right)$. We further denote the total sum of the external data as

$$
E_{t}=\sum_{j} D_{j, t}
$$

and define a perspective as having a "filtering" part $\left(P_{j, t}^{F}\right)$ to access and generate data, and a "learning" part $\left(P_{j, t}^{L}\right)$ to update $P_{j, t}^{F}$. All the modeling equations are summarized in Figure 8. Equation 1 states that stakeholder $j$ updates his or her internal information on the basis of total available external data by filtering the data through his or her perspective $\left(P_{j, t}^{F}\right)$ and combining it with the internal information $\left(H_{j, t}\right)$. Equation 2 states that this update of internal information causes his or her perspective to evolve in time. Equation 3 states that the external data a stakeholder generates at time $t+1$ are created by the updated perspective acting on the updated internal information. These dynamic equations represent stakeholders' perspectives as an "operator," which acts on the external data that are encountered and the external data that are produced. The produced external data, in turn, are encountered by other stakeholders and interpreted by their perspectives. Cycles continue throughout an STCP. 


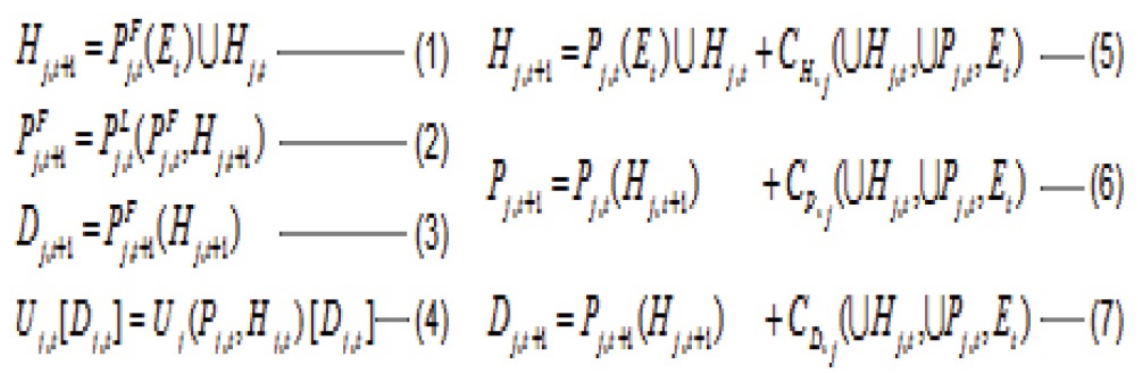

Figure 8. Dynamic system and feedback control model

With these basic operations defined, we can model an STCP as an "understanding-sharing" process among stakeholders. As seen in Equation 4, we define the understanding of a stakeholder $j$ at time $t,\left(U_{j, t}\right)$ as an operator that depends on his or her perspective and his or her internal information. The goal of an STCP in collaborative engineering is to make $U_{j, t}\left(D_{j, t}\right) \cap U_{k, t}\left(D_{l, t}\right)$ as "large" as possible for $t>m, D_{l, t} \in C(k, j)$, where $C(k, j)$ represents communication between stakeholders $k$ and $j$, and $m$ is a suitable time horizon. One way of enlarging stakeholders' common understanding is to influence the dynamic relations (Equations 1-4) using a set of "controls" specified in Equations 5-7 in Figure 8, in which the perspective acts as the coefficients and the perceived data as the values of the parameters. The result of applying these equations for a set of values is the internalized information or the externalized data. The adaptive feedback is a process that actively changes the coefficients. For example, controls $N j$ may be seen as collaborative negotiation activities. These three control equations (Equations 5-7) indicate that negotiation at the external data level $\left(N_{D, j}\right)$ alone is not enough to support collaboration in the socio-technical co-construction process. It is vital to encourage stakeholders to negotiate at the perspective $\left(N_{P, j}\right)$ and internal knowledge $\left(N_{H, j}\right)$ levels and to provide necessary social network information on involved stakeholders.

\subsection{Analyzing Stakeholder Perspectives to Manage Decision Conflicts}

With the above mathematical models of stakeholder perspectives, the next step in an STCP is to perform perspective analyses (Step 6, Section 7.2) to determine the current degree of agreement (or difference) among stakeholders. This step has three phases: (1) review perspective models in perspective model state diagrams (PMSDs) to establish a perspective distance matrix, (2) perform cluster analyses to determine the similarities and differences between stakeholder perspectives of a concept in CS, and (3) resolve conflict by minimizing the distance between stakeholder perspectives. These phases will be iteratively carried out, leading to a state in which the distances between stakeholder perspectives are either completely eliminated or are reduced to below a preagreed threshold.

In the first phase, stakeholders review perspectives in PMSDs and use some intuitive or analytical approaches to determine similarities/differences between perspectives $i$ and $j$, defined as "distance," $d_{i, j}$. The intuitive approach, for example, asks stakeholders to review their own PMSDs to derive $d_{i, j}$ independently. In other words, $d_{i, j}$ is determined by $d_{i, j}^{i}$ and 
$d_{i, j}^{j}$, specified by stakeholder $i$ and $j$, respectively; the final value of $d_{i, j}$ is the weighted average of these two estimations. With the analytical approach, perspective stakeholder models of a concept can be viewed as a network of elements associated with each other, called the perspective model network, which can be converted to a perspective interaction matrix. For example, Figure 9 illustrates a set of seven perspective models, using solid lines for "agreements" and dotted lines for "disagreements" between stakeholders' perspectives. Although the lines are typically unidirectional in a perspective model network, connections also can be multidirectional and depicted with multiple arrows, as shown in the figure.

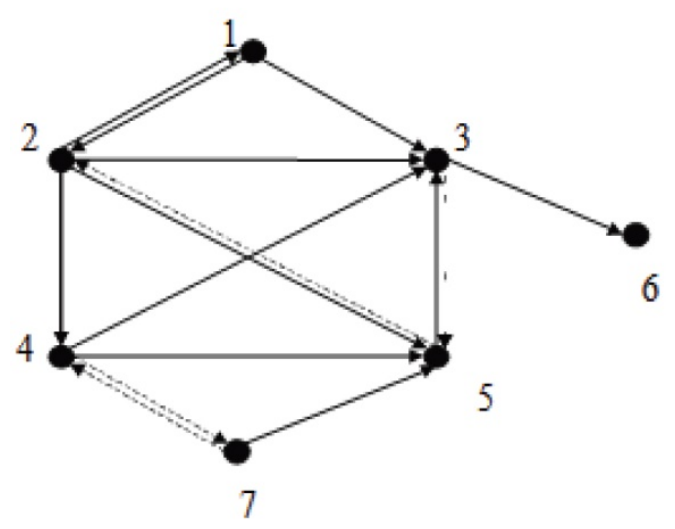

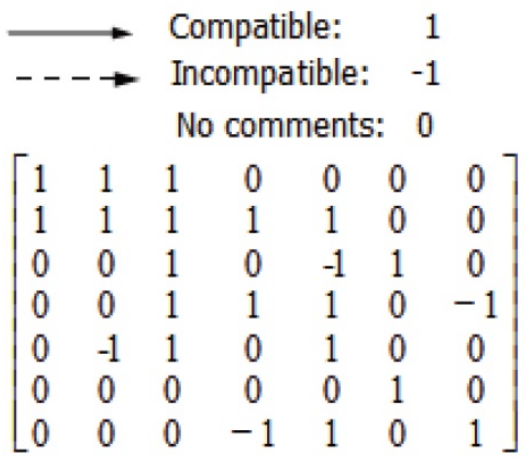

Figure 9. Perspective model network and matrix

By analyzing the structure and relationships of these perspective model networks and perspective interaction matrixes, we can determine similarities and differences among stakeholders' perspectives. If perspective models are structurally equivalent (i.e., their relationships with related perspective models are the same), they are treated as "compatible," with no detectable differences and are placed in the same "position" within the perspective model network. Otherwise, we can apply hierarchical clustering (both agglomerative and divisive) to the perspective interaction matrix to generate a tree structure (dendrogram) that partitions the interactions into subclasses (Figure 10). A cluster tree with a simple structure representing the similarities between stakeholders and fewer levels implies that all of the perspective models therein have similar attitudes toward. However, fewer levels do not always indicate a more uniform perspective model. The overall height of the cluster indicates the distance (i.e., dissimilarity) between perspective models. If most perspective models are within a cluster that is relatively short, then they are considered to be more compatible with each other. If the clustering levels are fairly high, then perspective models are more isolated from each other; this denotes that the perspective models are not readily shared. 
For two perspective models toward a concept:

$$
d_{i, j}=\sqrt{\sum_{k=1}^{g}\left[\left(x_{i k}-x_{j k}\right)^{2}+\left(x_{k i}-x_{k j}\right)^{2}\right]}
$$

For two stakeholders' perspective toward a group of concepts:

$$
d_{i, j}=\sqrt{\sum_{r=1}^{R} \sum_{k=1}^{g}\left[\left(x_{i k}-x_{j k}\right)^{2}+\left(x_{k i v}-x_{k j}\right)^{2}\right]} \begin{aligned}
& d(r, s)=\max \left(d_{i, j}\right), i \in\left(1, \ldots, n_{r}\right), j \in\left(1, \ldots, n_{s}\right) \\
& d(r, s)=\max \left(d_{i, j}\right), i \in\left(1, \ldots, n_{r}\right), j \in\left(1, \ldots, n_{s}\right)
\end{aligned}
$$

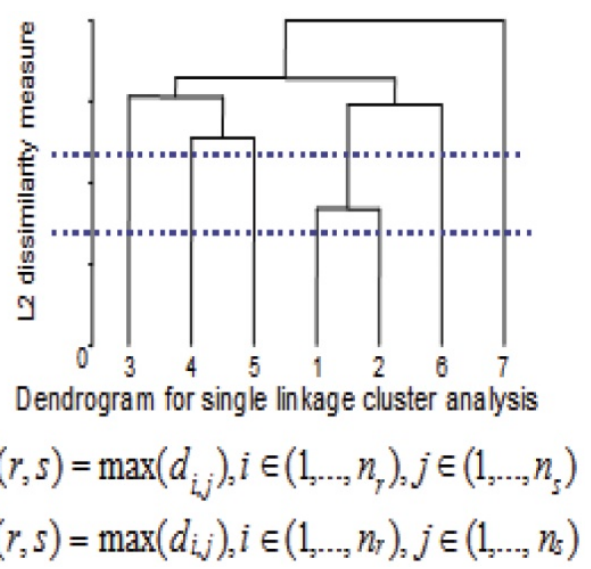

Figure 10. Perspective distances and cluster analyses

Despite many simplifications, the above mathematical models and analytical approaches can offer useful approximations of the changing perspectives of an individual in teamwork, so that we can conceptually understand stakeholders' social interactions during an STCP. It is through the integration and evolution of stakeholder perspectives, and updates of their internal information and external data, that we can understand the dynamic social interactions among stakeholders during collaborative engineering, hence contributing to the development of a collaborative engineering theory.

\section{An Industrial Case Study to Validate Our Collaborative Engineering Research}

This section presents an industrial case study of the commercial vehicle manufacturer DaimlerChrysler Truck Group (DCTG) to validate the collaborative engineering framework and approaches that have been described in this paper. We report on how DCTG employs a Global Innovation Management (GIM) strategy with regard to organizational, structural, and behavioral aspects of the collaborative engineering principles discussed in the paper. As a global organization that serves many local markets, DCTG uses GIM to achieve the difficult goal of balancing conflicting globalization and localization requirements. Specifically, the task of GIM is to realize the competing "scale" and "scope" effects in product planning and engineering process. The scale effects enable a global company to offer products at lower prices using mass production (i.e., the economy of scale). Meanwhile, customer requirements in different markets require consideration of local specifications and standards, which present many conflicting constraints to mass production. As indicated in Figure 11, GIM is essentially a dynamic "balancing act" between high production quantities and high product variations, two conflicting objectives that must be addressed by collaborative engineering. 


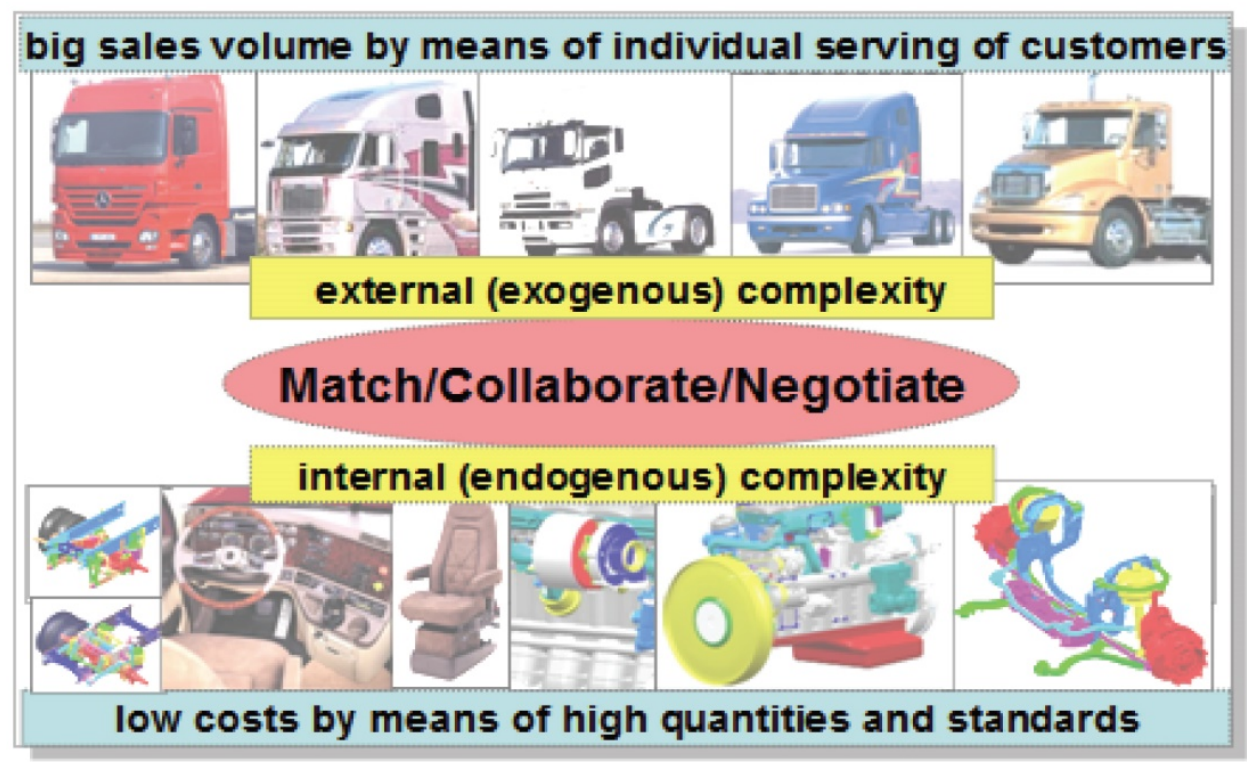

Figure 11. Conflicting interests in scale and scope

Product planning in GIM involves complex and interrelated activities that can be broken down into a five tasks. The first is to examine the market environment and its critical influences such as customer segments, competitors, market strategy, and technological trends. The second task is to design the product portfolio, which is then followed by the third task, which is to define the communality strategy of the product. The fourth task is to manage the product release, which leads to the final task of designing concrete development projects. The benefits and effects of our collaborative engineering approach are demonstrated specifically in relation to the third task, the management of global communality.

One of the main goals of communality management is to ensure the reuse of results from existing engineering processes to save manufacturing costs. Communality effects can be achieved in three different areas:

- Product communality: generating physically identical products and components by realizing a maximum of economies of scale.

- Technological communality: bundling technological core competencies to realize process and product robustness as well as flexible use of technologies.

- Engineering communality: using design similarity and corresponding methods (e.g., parametric design, design rules) for fast realization of product variants and exchangeability of product information

Communality management must tackle the conflicts between aiming to reduce production costs by the use of standards in product structure (global standardization) and trying to offer a range of individual products to local markets (regional adoption). 


\subsection{The Company and Problem Backgrounds}

The business of manufacturing commercial vehicles has changed rapidly over the last few decades. In the 1970s, approximately 40 manufacturers were in business worldwide. In 2005, this number was reduced to 15 companies that act in the triad markets. Despite this decrease, the world market has doubled over the last 20 years. As a result, several companies had to merge their product strategies, R\&D resources, and capabilities as well as production lines. They also responded to the challenge of joining different brands in one organization by integrating different market perspectives and quality.

DCTG is currently the biggest player in the commercial vehicle market. With 10 different brands, the company is operating at 64 sites across the globe. It develops, delivers, and sells products in different markets (e.g., NAFTA, Europe, Latin America, and Asia, especially Japan) featuring different brands (Freightliner, Sterling, and Western Star in Northern America, Mercedes-Benz in Europe, and Mitsubishi Fuso in Asian). DCTG sales presently exceed the sales of other competitors by more than a factor of two. Given that a company of such size should be able to benefit from the scale effects of their market position, DaimlerChrysler recently stated that DCTG has not been able to fully realize significant communality effects in former years as a result of separate brands and markets that were not integrated. Therefore in 2003, the management of DCTG set up a comprehensive change management program called "Turning Scale into Profit." The program strategy is to enable DCTG to profit from its position as world market leader by achieving cost advantages. The aim is to standardize, as much as possible, vehicles, components, and manufacturing parts, and to globally integrate these standards. For example, synergy effects might be achieved between the heavy Freightliner Truck and the Actros of DaimlerChrysler.

As a result of this program, DCTG developed a "communality roadmap" that describes effects on the level of the product, its suppliers, the production system, and the company's knowledge. It also built a new organization called Truck Product Creation (TPC) that changed the engineering and decision-making processes in the company. This case study highlights the principles of collaborative engineering and ECN at their core, even though DCTG does not characterize them as such.

\subsection{Shared Understandings and Perspectives}

Our ECN-based approach claims that the integration of different stakeholders' perspectives plays a significant part in collaborative engineering (Section 4). This claim raises a few practical questions, such as: (1) which decision-making process might be identified as relevant? (2) what kind of concept structure (CS) has to be decided on? and (3) who are the stakeholders? The joint decision process in global communality management must find answers to these questions, both in terms of the degree of communality with respect to the local adoption of vehicles, components, and manufacturing parts, as well as the degree of standardization in the product structure.

The degree of communality across the product program of DCTG can be obtained only by collaboration among multiple conflicting interests defined by different market requirements. For example, the Asian market requires small and agile commercial vehicles, whereas Northern American business demands trucks with a maximum load and capacity. Former organizational structures of DCTG did not take into account these different local 
requirements. Each market had its own representative who was responsible for his own local business. These representatives exercised a high degree of freedom in product planning, with the main goal and dominating perspective of increasing local market shares. Although this goal was in line with a pursuit of economies of scale, it failed to take advantage of the communality effects across multiple brands and markets. This insufficiency was also due to a lack of information and knowledge of how to influence product design in different markets in a communality-oriented manner.

The stakeholders involved in this decision process were the design experts who suggested an optimized product structure, the market representatives who argued that design must meet local demands, and the management who held the final decision-making authority. In the past, decisions about alternatives in product designs were made at higher levels of the organization. Due to this rigid structure, the information that reached the upper management was always reduced and filtered. With regard to the requirements of "common understanding" for collaborative engineering (Section 5.2), there was no feedback loop from management to technical experts and vice versa to achieve common understanding. The stakeholders could not obtain a shared reality because their resulting perspective distance was not transparent to all. There was a lack of consensus behind decisions, which often produced suboptimal results at best.

\subsection{Deployment of Collaborative Engineering}

The problems caused by the strictly market-oriented approach were one of the reasons that DCTG attempted the collaborative engineering approach to seek higher economic returns with greater cost reductions through better collective decisions in communality management. The main challenge was to achieve better consensus between multiple stakeholders, when addressing market demands and, at the same time, increasing the reusability of production technology and design platforms. Better collaborations had to be established to achieve synergy among the stakeholders' competing objectives and an amalgamation of their different perspectives. Four main changes characterize the restructuring of DCTG:

- Matrix structures that integrate product planning and product development (i.e., the matrix organization).

- Common understanding of product planning and development objective by defining global mandatory system architecture (i.e., the system architecture).

- Globally distributed component-oriented engineering groups to lead the development of specific truck components (i.e., the lead engineering team).

- Connection of all necessary resources in product planning and development processes via a network (i.e., global Truck Product Creation: TPC network).

The matrix organization enhances the collaboration between the market-oriented perspectives of the different brands with the communality-oriented perspective of product development. Within this new structure, the system architecture defines the concept of product development by delivering its main structuring criteria. The new system architecture is divided into four main subsystems: cab (common cab architecture), chassis (common frame architecture), mechatronics (common E/E architecture), and powertrain (heavy 
duty and medium duty engine family, heavy duty transmission portfolio). The matrix organization can link the vehicle and brand structure to the system's architecture, hence enabling collaboration between different brands and markets.

Another key element in this collaborative engineering approach is the lead engineering team (LET). A lead engineering team represents equally the stakeholder perspectives of manufacturing, procurement, and engineering. Each team consists of a lead manufacturing engineer, a lead buyer, and a lead design engineer who work at the same level in the organizational hierarchy, and each collaborates closely with his or her regional counterparts. Each team is directly linked to one of the four main subsystems in the system architecture. A total of 52 LETs was established for the development of special components (e.g., motor, transmission, axis of the truck). The use of collaborative LETs improves global collaboration in component development of the vehicles. The main advantage of these lead engineering teams is the harmonization of component development across various product portfolios. All stakeholders act at the same level of the organizational hierarchy to promote and ensure a highly collaborative joint decision-making process. Another important effect on DCTG is the implementation of the TPC-Network. It achieves global coverage of all development elements and involves fewer hierarchy levels and biases compared to the former brand-oriented structures. It integrates product planning with regional foci on brand and production planning with global standardization of components.

The conflicting objectives between scales and scopes can now be discoursed systematically and resolved competently, leading to participative joint decisions that underlie the final agreement to which all stakeholders are committed. This collaborative engineering approach further improves development of product portfolios and leads to joint development projects across brands and markets. The resulting projects deliver the basis for the targeted cost reduction effects, including the reuse of manufacturing parts (e.g. motor, air conditioning system, gear boxes), the definition of global systems and architectures (e.g., breaks, cabin, electronics), and the development of regional-specific components for local market needs. As a result, the variety of components and the product costs are reduced significantly. An example of this integration of product components from different brands and the reduction of future component variants in chassis are presented in Figure 12.

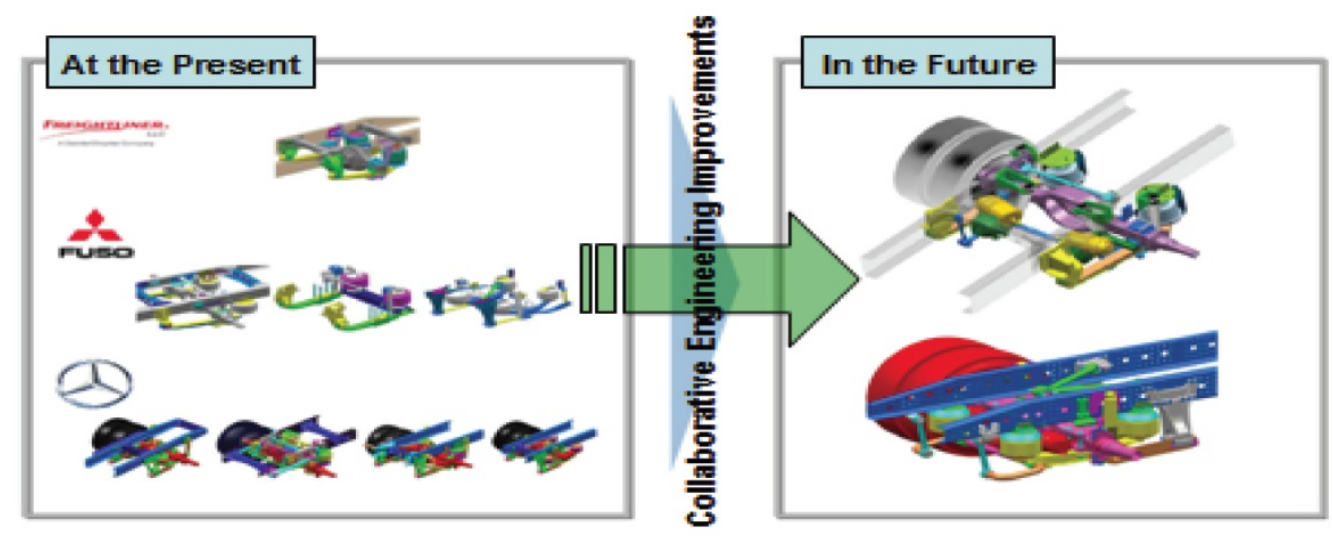

Figure 12. Resulting reductions in variants in chassis 


\subsection{STCP for a Cross Member of the Truck Chassis}

To illustrate the applications of collaborative engineering and ECN on DCTG, this part of the case study presents a description of a concrete decision task, i.e., how to manufacture a cross member part, as part of the global communality management at DCTG. The function of the cross member, as a part of the truck's chassis, is to connect different modules of the chassis and to transmit the load of connected components. It is also the main part of the truck's structure and is assembled in every kind of vehicle, regardless of the brand or size of the truck. The challenge in this decision task is to decide on how to take advantage of different communality effects in order to reduce part cost during manufacturing.

According to Step 1 of an STCP (Section 7.2), the baseline process for this decision task is typically provided by the company's internal global change management process. This process is mainly initiated by corporate functions, such as procurement or engineering, which are responsible for the continuous reduction of product costs. The main steps in the change management process include, for example, initiation of the process, verification of change impact (functional and financial), collection of necessary data to evaluate change request (e.g., via suppliers, development, manufacturing), collaborative evaluation of the change request and final discussion in the lead engineering group. The stakeholders (Step 2 of an STCP) who participate in the baseline process are members of a lead engineering team from the three involved brands (i.e., Freightliner, Mercedes-Benz, Mitsubishi Fuso) and other relevant functional disciplines (e.g., manufacturing, procurement, engineering). The typical number of stakeholders involved in this collaborative engineering endeavor is nine. Due to the cost reduction objective, the team had to develop a concept for a cross member that allowed for a maximum of communality across all brands. Another requirement was to enable integration of this component in the different chassis concepts of the brands. The initial concept structure (Step 3 of an STCP) promoted the adaptation of one common cross member for all vehicles in the product portfolio. The intended communality effects (i.e., commercial advantage of the change request) were in purchasing (i.e., higher purchasing volume leading to a reduced supplier price) and engineering (i.e., developing one cross member as opposed to multiple parts). During the collaborative engineering process, three perspectives of the conceptual structure were gathered from different stakeholders with respect to different brand requirements (Steps 4 and 5 of an STCP):

- Perspective 1: European trucks had no restriction, using only one common cross member.

- Perspective 2: Asian cross member concepts are based on different steels with different parameters (e.g., elastic modulus or tensile strength). Therefore, the Asian perspective was that a global communality part would fail due to functional aspects.

- Perspective 3: The North American aftermarket has special requirements concerning the easy assembly and disassembly of cross members. Hence, this stakeholder asked for a second, special engineered variant for the North American aftermarket.

Other functional considerations that influence collective decisions of possible communality for the cross member are width and height of the part as well as preferences for 
material, including its impact on the geometry and design of the part. As a result of the perspective analysis (Step 6 of an STCP) of involved stakeholders, the distances (i.e., conflicts) between different perspectives, which were to be reduced, were of both commercial and functional natures. Two specific considerations led to the resolution of these conflicts (Step 7 of an STCP). First, the functional and technical feasibility of a common cross member concept was proven. After positive proof of the technical concept, the commercial impacts on Freightliner, Mercedes-Benz, and Mitsubishi Fuso were then evaluated. The single commercial cases for each brand were negative, but over the whole group were positive. The reasons for this were possible scale effects and the closer integration of local suppliers. After final discussion, every stakeholder was convinced of the common cross member concept. A shared reality (Step 8 of an STCP) was obtained, based on this new knowledge of cross brand communality effects. Without an STCP, the common part concept for the cross member would not have been realized. The collaborative engineering approach successfully enabled the company to reduce the overall part costs.

\subsection{Positive Effects of Collaborative Engineering}

The industrial case study of the DCTG demonstrates the positive effects of collaborative engineering and ECN applications. The new matrix organization, with clear system architecture and lead engineering teams that facilitate participative joint decision processes, delivered a broader variety of satisfying solutions and alternatives for complex engineering tasks. The collaborative decision-making process is less biased by rigid, single-minded, or isolated perspectives. As a result, a considerable number of executives have been positively influenced by the additional outcomes of this kind of collaborative decision-making. Further, the approach of company-wide concept discussions and benchmarking contests produced positive effects, such as an enhanced willingness to find innovative solutions and reduction of the not-invented-here phenomenon as well as a new corporate culture shared by all stakeholders. The DCTG case study shows that ECN has the power to significantly widen the potential for profit. In the case of DCTG, the communality potential for future truck products is estimated to be $80-90 \%$ between the brands of Mercedes-Benz and Mitsubishi Fuso alone. The communality potential between all brands is at least $50-60 \%$. Employing collaborative engineering principles is a promising way of achieving these communality effects.

\section{Summary and Conclusion}

Production engineering is the most dynamic discipline of the engineering profession and one that must take on more social responsibilities. The ultimate success of this discipline depends on our vision and ability to initiate, lead, and act as the "change agent" for the important technological, economic, social, and geo-political developments that are revolutionizing our world. Some of these developments, such as novel materials and new processes and machines, are of a purely technical nature and, as such, can be systematically understood, developed, and applied by studying their corresponding disciplines in natural sciences. Others, such as new integration approaches, management methodologies, and production paradigms, involve complex human activities and social factors that go beyond 
pure technical considerations. The understanding and practices of these new socio-technical developments at the system level of production engineering require broader knowledge of human beings, organizations, and society, outside of the scope of traditional engineering research based on natural sciences. Collaborative engineering is such a socio-technical development that is rapidly shaping the global production industry today, and it will significantly change the ways we do production engineering tomorrow. The human-centered, practice-based, and socio-technical features of collaborative engineering present a great challenge for the engineering research community.

Regardless of one's position toward the intellectual values of collaborative engineering research, no one can doubt the importance of collaboration in improving our industrial competitiveness. Despite the few successes that have been achieved by some companies with collaborative engineering approaches to date, the great demand for better collaboration support by the industry as a whole has put a strain on our basic understanding of this subject. Without improved knowledge, better theories, and more systematic methods and robust tools, the current ad-hoc applications of collaborative engineering ideas cannot sustain the test of time and will not result in long-lasting impacts. In support of increasing globalization, we have taken the first step to fulfill our responsibility of generating a better and more scientific understanding of collaborative engineering. The foundation, definition, hypothesis, framework, and process described in this paper should be seen as a "stepping stone" for the entire engineering community to begin scientific undertakings that can eventually lead to the development of sound collaborative engineering theories. Just like the tremendous growth experienced by the power industry after thermodynamics theories became available, we believe that the production industry will enjoy many revolutionary advances once collaborative engineering theories are established.

Time Magazine's 2006 Person of the Year selection of "You" was a clear reflection that the high-connected world we live in today is very different from that of the last century. It recognizes people and organizations that are coming together to collaboratively shape the future in virtually every sphere of our lives around the world. More than ever, we are not merely passive observers but active participants in a world that we are jointly creating. As collaboration has become a vital part of our industry and society, it is a good time to recall Albert Einstein's words: “The world we have created is a product of our thinking. It cannot be changed without changing our thinking." The ultimate goal of our collaborative engineering research is to change the current thinking toward many engineering tasks that are intrinsically human-centered and must be pursued by socio-technical means. The potential impacts of these efforts go beyond just engineering productivity in industry and economic competitiveness of our society. The continuous and rigorous quests for collaborative engineering research will ultimately expand our proper understanding of "engineering" as a scientific discipline and the true challenge of "engineering" as a practical profession. We believe that a completely new frontier for "the broader discipline of engineering" can be gradually discovered through the scientific pursuits of collaborative engineering. The specific research efforts described in this paper represent a small step for engineers, but a giant step for engineering! 


\section{Acknowledgments}

We acknowledge the material contributions from L. Alting; G. Chryssolouris; A. Kjellberg; T. Kjellberg; M. Leu; A. Nee; G. D. Putnik; S. Schoening; G. Seliger; G. Sohlenius; N. P. Suh; and H-P. Wiendahl. We also appreciate many intellectual contributions and constructive criticisms that we have received from all CIRP/ECN-WG members and their guests who have actively participated in our ECN meetings over the past few years. The collegial environment and diverse expertise in CIRP have greatly contributed to the initiation and development of this interdisciplinary subject. Especially, continuous encouragement from a few of our senior CIRP colleagues, including M. E. Merchant, P. Peklenik, G. Sohlenius, and N .P. Suh, has been a major inspiring force behind our efforts. Some of the research results described in Sections 5 and 6 were developed at the Improving Productivity with Advanced Collaboration Technology (IMPACT) laboratory at the University of Southern California. We are grateful to the students and sponsors of IMPACT who made these results possible. The industrial case study presented in Section 8 was conducted by WZL, RWTH Aachen with the DaimlerChrysler Truck Group (DCTG). We greatly appreciate the supports from DCTG engineers and management. We also thank the valuable editorial assistance of Dr. Sharon Bear. Although the results presented in this paper have been pursued by many colleagues collaboratively, the potential errors are the sole responsibility of the author.

\section{References}

[1] Alting, L. A., M. M., Boelskifte, P., Clausen, C., Jørgensen, U., 2006, Design and InnovationThe DTU Program, International CIRP Design Seminar, 1-8, Calgary, Canada.

[2] Tseng, M. M., Kjellberg, T., Lu, S. C-Y., 2003, Design in the New E-Commerce Era, Annals of the CIRP, 52/2: 43-54.

[3] Lu, S. C.-Y., 2006, Beyond Concurrent Engineering: a New Foundation for Collaborative Engineering, International Journal of Advanced Manufacturing Systems, 9/2: 27-40.

[4] Todd, S., 1992, Collective Action: Theory and Application, University of Michigan Press.

[5] Hammond, J. H., Koubek R. J., Harvey C. M., 2001, Distributed Collaboration for Engineering Design: A Review and Reappraisal, Human Factors and Ergonomics in Manufacturing, 11/1: 35-52.

[6] Hazelrigg, G. A., 1996, The Implications of Arrow's Impossibility Theorem on Approaches to Optimal Design, ASME Journal of Mechanical Design, 118/2: 161-164.

[7] Sohlenius, G., 2006, Theory of Knowledge and Scientific Base of Industrial Innovation (a book chapter draft).

[8] Lu, S. C.-Y., 2005, Engineering Collaboration via Negotiation, CIRP ECN-WG Special Workshop, informal WG publication, Shanghai, China.

[9] Arrow, K. J., 1963, Social Choice and Individual Values, Wiley Publishers, New York.

[10] Hazelrigg, G. A., 1998, Framework for Decision-Based Engineering Design, Journal of Mechanical Design, Transactions of the ASME, 120/4: 653-658.

[11] Scott, M. J., Antonsson, E. K., 1999, Arrow's Theorem and Engineering Design Decision Making, Research in Engineering Design, 11/2: 218-228.

[12] Von Neumann, J., O. Morgenstern, 1944, Theory of Games and Economic Behavior, Princeton University Press.

[13] Simon, H. A., 1996, The Science of the Artificial, MIT Press, Cambridge, MA. 
[14] Kuhn, T. S., 1996, The Structure of Scientific Revolutions, University of Chicago Press, Chicago, IL.

[15] Shah, J., Finger, S., Lu, S. C-Y., Leifer, L., et. al., 2005, ED2030: Strategic Plan for Engineering Design, NSF Design, Manufacturing and Industrial Innovation Grantees Conference, Tempe, Arizona.

[16] CIRP/ECN-WG, 2003, Engineering Collaboration via Negotiation (ECN)-a CIRP Working Group, Sponsored by: CIRP STCs on Assembly, Design, and Optimization, Paris, France.

[17] CIRP/ECN-WG, 2005, ECN-WG August 2005 Meeting Minutes, 2005 General Assembly Meeting, Antalya, Turkey.

[18] Mills, A., 1998, Collaborative Engineering and the Internet, Society of Mechanical Engineers, Dearborn, Michigan.

[19] Lu, S. C.-Y., Sundararajan, S., 1991, A Cooperative Distributed Problem Solving Framework, International J. of Applied Artificial Intelligence in Engineering, 46/6: 114-128.

[20] Papalambros, P. Y., Wilde, D. J., 2000, Principles of Optimal Design: Modeling and Computation, Cambridge University Press.

[21] Keeney, R. L., Raiffa, H., 1993, Decisions with Multiple Objectives: Preference and Value Tradeoffs, Cambridge University Press, Cambridge.

[22] Franssen, M., 2005, Arrow's Theorem, Multi-criteria Decision Problems and Multi-attribute Preferences in Engineering Design, Research in Engineering Design, 16/2: 42-56.

[23] Bauer, H. H., 1994, Scientific Literacy and the Myth of the Scientific Method, Univ. of Illinois, Urbana, IL.

[24] Lu, S. C.-Y., et. al., 2004, Social Aspects of Engineering Design: Final Report of Working Group III, 2004 NSF Strategic Planning Workshop on Engineering Design in 2030, Gold Canyon, Arizona.

[25] Lu, S. C.-Y., Li, Q., Case, M., and Grobler, F., 2006, A Socio-technical Framework for Collaborative Product Development, Transactions of the ASME, Journal of Computing and Information Science in Engineering, 6/2: 160-169.

[26] NCMS, 1996, Collaborative Engineering Agenda, Ann Arbor, MI.

[27] Knoth, J., 1996, Engineering via the Internet, Computer-aided Engineering, Loveland, Colorado.

[28] VIVACE, 2005, Collaborative Methods and Tools, VIVACE Forum, CERFACS, EADS, Warwick, U.K.

[29] Smith, S. S.-F., 2004, An Evaluation of Internet-Based CAD Collaboration Tools, The Journal of Technology Studies, 79-85.

[30] Lu, S. C.-Y., Shpitalni, M., Bar-Or, R., Gadh, R., 1999, Virtual and Augmented Reality Technologies for Product Realization, Annals of the CIRP, 48/2: 471-495.

[31] Stasser, G., Titus, W., 1985, Pooling of Unshared Information in Group Decision Making: Biased Information Sampling During Discussion, Journal of Personality and Social Psychology, 48/5: 1467-1478.

[32] Suh, N. P., 2000, Axiomatic Design-Advances and Applications, Oxford University Press, Cambridge.

[33] Sriram, R., Szykman, S., Durham, D., 2006, Special Issue of Collaborative Engineering, Journal of Computing and Information Science in Engineering, Transactions of the ASME, 6/2: 93-95.

[34] Sriram, R., 2002, Distributed Integrated Collaborative Engineering Design, Sarven Publishers. 
[35] Snijders, T., 2005, Models for Longitudinal Network Data, Cambridge University Press, Cambridge, UK.

[36] Kuutti, K., Arvonen, T., 1992, Identifying Potential CSCW Applications by Means of Activity Theory Concepts: A Case Example, Computer Supported Collaborative Work (CSCW) 92 Proceedings, ACM, 233-240.

[37] Erickson, T., Kellogg, W. A., 2000, Social Translucence: An Approach to Designing Systems That Support Social Processes, ACM Transactions on Computer-Human Interactions, 7/1: 59-83.

[38] Heckel, J., Ganeshan, R., Case, M., Lu, S. C-Y., Baskin, A. B., 1997, The Virtual Workspace System: An Enabling Technology for Collaborative Engineering Applications, Proceedings of the Workshop on Enabling Technologies for Collaborative Enterprise, Boston, MA.

[39] Toulmin, S., Rieke, R., Janik, A., 1979 and 1984, Uses of Argument (Chapter 3), An Introduction to Reasoning, Macmillan, New York, NY.

[40] Rahwan, I., Ramchurn, S. D., Jennings, N. R., McBurney, P., Parson, S., Sonenberg, L., 2004, Argumentation-based Negotiation, The Knowledge Engineering Review, 18/4: 343-375.

[41] Lu, S. C.-Y., Jing, N., 2006, A Socio-technical Negotiation Approach for Collaborative Design in Software Engineering, International Journal of Collaborative Engineering, 1/1, to appear.

[42] Shen, W., Norrie, D. H., 2000, Multi-Agent Systems for Concurrent \& Intelligent Design \& Manufacturing, Taylor and Francis, London, UK.

[43] Monostori, L., Váncza, J., Kumara, S. R. T., 2006, Agent-based Systems for Manufacturing, Annals of the CIRP, 52/2: 697-721.

[44] Jin, Y., Lu, S. C-Y., 1998, An Agent Supported Approach to Collaborative Design, Annals of the CIRP, 47/1: 107-110.

[45] Shen, W., Barthès J., 1995, DIDE: A Multi-agent Environment for Engineering Design, Proceedings of the First International Conference on Multi-Agent Systems (ICMAS).

[46] Lavana, H., Brglez, F., Reese, R., Konduri, G., Chandrakasan, A., 2000, OpenDesign: An Open User-configurable Project Environment for Collaborative Design and Execution on the Internet, Proceedings of International Conference on Computer Design, 567-570.

[47] Huang, G. Q., Mak, K. L., 1999, Web-based Collaborative Conceptual Design, Journal of Engineering Design, 10/2: 183-194.

[48] Cutkosky, M. R., Glicksman, J., Tenenbaum, J. M., 1996, MadeFast: Collaborative Engineering Over the Internet, Communications of the ACM, 39/9, 78-87.

[49] Pahng, F., Bae S., Wallace D., 1998, A Web-based Collaborative Design Modeling Environment, IEEE Workshop on Enabling Technologies Infrastructural for Collaborative Enterprise, 161-167.

[50] Park, H., 2003, An Internet-Based Collaborative Engineering System, Lecture Notes in Computer Science, Web Engineering, Springer Berlin.

[51] Kim, D., Bufardi, A., Xirouchakis, P., 2006, Compatibility Measurement in Collaborative Conceptual Design, Annals of CIRP, 55/1: 151-154.

[52] Hauck, S., Knol, S., 1998, Data Security for Web-based CAD, Proceedings from Design Automation Conference, 788-793.

[53] Wang, L. Shen, W. Xie, H. Neelamkavil, J. Pardasani, A., 2002, Collaborative Conceptual Design-State of the Art and Future Trends, Computer-Aided Design, 34/13: 981-996.

[54] Park, H., Cutkosky, M. P., 1999, Framework for Modeling Dependencies in Collaborative Engineering Processes, Research in Engineering Design, 11/2: 84-109. 
[55] Baskin, A. B., Lu, S. C-Y., Ganeshan, R., Case, M., 1997, Collaborative Workspace: Sharing Emerging Product Models Across Disciplines, Space and Time, Proceedings of the Concurrent Engineering Workshop, Troy, NY.

[56] Lu, S. C.-Y., Cai J., 2000, STARS: A Socio-Technical Framework for Integrating Design Knowledge over the Internet, IEEE Internet Computing, 3/5: 54-62.

[57] Girod, M., Elliott A. C., Burns N. D., Wright, I. C., 2003, Decision Making in Conceptual Engineering Design: an Empirical Investigation, Proceedings of the Institution of Mechanical Engineers, Journal of Engineering Manufacture, 1215-1228.

[58] Smith, R. G., 1980, The Contract Net Protocol: High-level Communication and Control in a Distributed Problem Solver, IEEE Trans. on Computers, 12/8.

[59] Palazzolo, E. T., 2003, Structures of Communication to Retrieve Information in Organizational Work Teams: A Transactive Memory Perspective, Speech Communication.

[60] Monge, P., Fulk, J., 2003, Knowledge Networks and Distributed Intelligence, Professional Development Workshop, Academy of Management, Seattle, Washington.

[61] Wegner, D. M., 1987, Transactive Memory: A Contemporary Analysis of Group Mind, Springer-Verlag, New York.

[62] Olson, M., 1965, 1971, The Logic of Collective Action: Public Goods and the Theory of Groups, Harvard University Press.

[63] Contractor, N. S., Monge, P. R., 2002, Managing Knowledge Networks, Management Communication Quarterly, 16/4: 249-258.

[64] Monge, P. R., Contractor, N. S., 2003, Theories of Communication Networks, Oxford University Press.

[65] Ancona, D. G., Kochan, T. A., Scully, M., van Maanen, J., Westney. E. D., 1999, Organizational Behavior and Process, South-Western College Publishing.

[66] Fisher, B. A., 1970, Decision Emergence: Phases in Group Decision-Making, Communication Monographs, 37/2: 53-66.

[67] Thurston, D. L., 2001, Real and Misconceived Limitations to Decision-Based Design with Utility Analysis, Journal of Mechanical Design, Transactions of the ASME, 123/2: 176-182.

[68] Fudenberg, D., Tirole, J., 1983, Game Theory, MIT Press, Cambridge, MA.

[69] Nash, J. F., 1950, The Bargaining Problem, Econometrica, 18/1: 155-162.

[70] Mathieu, J., Goodwin, G., Heffner, T., Salas, E., Cannon-Bowers, J., 2000, The Influence of Shared Mental Models on Team Process and Performance, Journal of Applied Psychology, 85/2: 273-283.

[71] Wetmore III, W. R., Summers, J., 2003, Group Decision Making: Friend or Foe? IEEE International Engineering Management Conference, 405-409.

[72] Huang, G., 2002, Web-Based Support for Collaborative Product Design Review, Computers in Industry, 48/1: 71-88.

[73] Janis, I. L., 1971, Victims of Groupthink, Houghton Mifflin, Boston.

[74] Vaughan, D., 1996, The Challenger Launch Decision: Risky Technology, Culture and Deviance at NASA, University of Chicago Press, Chicago, IL.

[75] 1986, Investigation of the Challenger Accident; Report of the Committee on Science and Technology, US Government Printing Office.

[76] Boujut, J.-F., Tiger, H., 2002, A Socio-Technical Research Method for Analyzing and Instrumenting the Design Activity, Journal of Design Research, 2/7. 
[77] Majchrzak, A., Borys, B., 2001, Generating Testable Socio-Technical Systems Theory, Journal of Engineering and Technology Management, 18/2: 219-240.

[78] Larsson, A., 2002, Socio-Technical Aspects of Distributed Collaborative Engineering, Ph.D. thesis from Department of Applied Physics and Mechanical Engineering, Lulea Univ. of Technology, Sweden.

[79] Hacker, M., Kleiner, B., 1996, Identifying Critical Factors Impacting Virtual Work Group Performance, IEEE International Engineering Management Conference, Piscataway, NJ, 201-205.

[80] Bul, T. X., Slvasankaran, T. R., 1990, Relation between GDSS Use and Group Task Complexity, The 23rd Annual Hawaii International Conference on System Sciences, Hawaii, 69-78.

[81] Carey, J. M., Kacmar, C. J., 1997, The Impact of Communication Mode and Task Complexity on Small Groups Performance \& Member Satisfaction, Computers in Human Behavior, 13/1: 23-49.

[82] King, N., Majchrzak, A., 1996, Concurrent Engineering Tools: Are the Human Issues Being Ignored? IEEE Transactions on Engineering Management, 43/2: 189-201.

[83] Raiffa, H., 1982, The Art and Science of Negotiation: How to Resolve Conflicts and Get the Best Out of Bargaining, Belknap Press of Harvard University.

[84] Weiler, M., Lu, S. C.-Y., 1997, Maximize Customer Satisfaction in a Product Design Process by Using Engineering as Collaborative Negotiation Paradigm and the Dynamic Negotiation Model, The CIRP International Design Seminar on Multimedia Technology for Collaborative Design and Manufacturing, Los Angeles, CA, 29-36.

[85] Buyukozkan, G., Feyzioglu, O., 2005, Group Decision Making to Better Respond to Customer Needs in Software Development, Computers and Industrial Engineering, 48/2: 427-441.

[86] Cowan, F. S., Alien, J. K., Mistree, F., 2006, Functional Modelling in Engineering Design: A Perspectival Approach Featuring Living Systems Theory, Systems Research and Behavioral Science, 23/3.

[87] Jennings, N. R., Parsons, S., Noriega, P., Sierra, C., 1998, On Argument-based Negotiation, Proceedings of IWMAS 98.

[88] Cooper, S., Taleb-Bendiab, A., 1998, CONCENSUS: Multi-party Negotiation Support for Conflict Resolution in Concurrent Engineering Design, Journal of Intelligent Manufacturing, 5/1: 155-159.

[89] Li, D., Lu, S. C.-Y., Cheng, J., Wu, C. L., 1997, A Model Fusion Approach to Support Negotiations during Complex Engineering System Design, Annals of the CIRP, 46/1: 89-92.

[90] Adelson, B., 1999, Developing Strategic Alliances: A Framework for Collaborative Negotiation in Design, Research in Engineering Design, 11/3: 133-144.

[91] Lu, S. C.-Y., 2004, Collaborative Negotiation in Engineering Design: A Postmodern Approach to Systems Engineering, the 2004 NASA Workshop on Decision-Based Design Structures for Space Missions, Long Beach, California.

[92] Lu, S. C. Y., Cai J., Burkett W., Udwadia F., 2000, A Methodology for Collaborative Design Process and Conflict Analysis, Annals of the CIRP, 49/1: 69-73.

[93] Reddy, S., Lu, S. C-Y., 1995, An Interactive Refinement Methodology for Early Stage Exploration of Design Space during System Design, Annals of the CIRP, 43/1: 115-120.

[94] Prakash, A., Knister, M. J., 1994, A Framework for Undoing Actions in Collaborative Systems, ACM Transactions on Computer-Human Interaction, 1/4: 295-330.

[95] Ge, P., Lu, S. C-Y., Bukkatnam S. T-S., 2005, Supporting Negotiations in the Early Stage of Large-Scale Mechanical System Design, Journal of Mechanical Design, 127/6: 1056-1067. 
[96] Kjellberg, A., 1993, Principles of Multidisciplinary Cooperation in Research, Especially Behavioural Science and Manufacturing, Annals of the CIRP, 42/1: 164-168.

[97] Boër, C. R., El-Chaar, J., Imperio, E., Aval, A., 1991, Criteria for Optimum Layout Design of Assembly Systems, Annals of the CIRP, 40/1: 415-418.

[98] Brinksmeier, E., Popp, C., 1991, A Self-Tuning Adaptive Control System for Grinding Processes, Annals of the CIRP, 40/1: 129-132.

[99] Mäntylä, M., Lagus, K., Laakko, T., Sohlenius, G., 1994, Application of Constraint Propagation in Part Family Modelling, Annals of the CIRP, 43/1: 129-132.

[100] Nassef, A. O., ElMaraghy, H. A., 1997, Allocation of Geometric Tolerances: New Criterion and Methodology, Annals of the CIRP, 46/1: 101-104.

[101] Alting, L. J., J., 1993, The Life Cycle Concept as a Basis or Sustainable Industrial Production, Annals of the CIRP, 42/1: 163-166.

[102] Kimura, F., Lipson, H., Shpitalni, M., 1998, Engineering Environments in the Information Age: Research Challenges and Opportunities, Annals of the CIRP, 47/1: 87-90.

[103] Krause, F.-L., Kind, C., 1998, Strategic Planning of Information Technological Infrastructures for Life Cycle Management, Annals of CIRP, 47/1: 129-132.

[104] Noël, F., Tichkiewitch, S., 2004, Shared Dynamic Entities Technology to Support Distant Coordination in Design Activity, Annals of CIRP, 53/1: 163-166.

[105] Lindberg, L., Sohlenius, G., 1993, Notes on Concurrent Engineering, Annals of the CIRP, 42/1: 159-162.

[106] Reddy, S., Lu, S. C-Y., 1994, An Interactive Refinement Methodology for Early Stage Exploration of Design Space During System Design, Annals of the CIRP, 43/1: 115-118.

[107] Ueda, K., Nishino, N., Oda, S.H., 2003, Integration of Economics into Engineering with an Application to Recycling Market, Annals of the CIRP, 52/1: 33-36.

[108] Züst, R., Caduff, G., Schumacher, B., 1997, Life-Cycle-Modeling as an Instrument for Life-CycleEngineering, Annals of the CIRP, 46/1: 351-354.

[109] Scholz-Reiter, B., Höhns, H., Hamann, T., 2004, Adaptive Control of Supply Chains: Building Blocks and Tools of an Agent-based Simulation Framework, Annals of the CIRP, 53/1: 353-356.

[110] Tichkiewitch, S., Véron, M., 1997, Methodology and Product Model for Integrated Design Using a Multiviews System, Annals of the CIRP, 46/1: 81-84.

[111] Noel, F., Brissaud, D., Tichkiewitch, S., 2003, Integrative Design Environment to Improve Collaboration between Various Experts, Annals of the CIRP, 52/1: 109-112.

[112] Maropoulos, P. G., Crookall, J., 1999, Aggregate Product and Process Modeling for the Welding of Complex Fabrications, Annals of the CIRP, 48/1: 401-404.

[113] Jin, Y., Li, W., Lu, S. C-Y., 2005, A Hierarchical Co-Evolution Approach to Conceptual Design, Annals of the CIRP, 54/1: 155-159.

[114] Molloy, E., Yang, H., Browne, J., Davies, B. J., 1991, Design for Assembly within Concurrent Engineering, Annals of the CIRP, 40/1: 107-110.

[115] Domazet, D., Lu, S. C-Y., Kalajdzic, M., 1992, Concurrent Design and Process Planning of Rotational Parts, Annals of the CIRP, 41/1: 181-184.

[116] Wilhelm, R. G., Lu, S. C.-Y., 1992, Tolerance Synthesis to Support Concurrent Engineering, Annals of the CIRP, 41/1: 197-200.

[117] Herman, A., Lawley, M., Lu, S. C.-Y., Mattox, D., 1993, An Opportunistic Approach to Process Planning within a Concurrent Engineering Environment, Annals of the CIRP, 42/1: 545-549. 
[118] Krause, F. L., Kiesewetter, T., Kramer, S., 1994, Distributed Product Design, Annals of the CIRP, 43/1: 149-152.

[119] Kimura, F., Suzuki, H., 1989, A CAD System for Efficient Product Design Based on Design Intent, Annals of the CIRP, 38/1: 149-152.

[120] Lutters, D., Wijnker, T. C., Kals, H. J. J., 1999, Management in Process Planning, Annals of the CIRP, 48/1: 385-388.

[121] Brissaud, D., Zwolinski, P., 2004, End-of-Life-Based Negotiation throughout the Design Process, Annals of the CIRP, 53/1: 155-158.

[122] Elbestawi, M. A., Bone, G. M., Tam, P. W., 1992, An Automated Planning, Control and Inspection System for Robotic Deburring, Annals of the CIRP, 41/1: 397-400.

[123] Westkämper, E., Warnecke, H. J., 1994, Zero-defect Manufacturing by Means of a Learning Supervision of Process Chains, Annals of the CIRP, 43/1: 405-408.

[124] Blumfield, A., Shpitalni, M., Lenz, E., 1992, A Generator for Creating Adaptive Post Processors, Annals of the CIRP, 41/1: 527-530.

[125] Jiao, J., Tseng, M. M., 2003, Customizability Index Based on Information Content, Annals of the CIRP, 52/1: 121-124.

[126] Chen, S. L., Tseng, M. M., 2005, Defining Specifications for Custom Products: A Multi-Attribute Negotiation Approach, Annals of the CIRP, 54/1: 159-162.

[127] Sivard, G., Lindberg, L., Agerman, E., 1993, Customer Based Design with Constraint Reasoning, Annals of the CIRP, 42/1: 139-142.

[128] du Preez, N., Perry, N., Candlot, A., Bernard, A., Uys, W., Louw, L., 2005, Customised Highvalue Document Generation, Annals of the CIRP, 54/1: 123-126.

[129] Markus, A., Vancza, J., Kovacs, A., 2002, Constraint-based Process Planning in Sheet Metal Bending, Annals of the CIRP, 51/1: 425-429.

[130] Krause, F.-L., Golm, F., 1996, Planning and Multicriteria Optimization of Design Processes, Annals of the CIRP, 45/1: 145-149.

[131] Ueda, K., Hatono, I., Fujii, N., Vaario, J., 2001, Lineless Production System Using Self-Organization: A Study for BMS, Annals of the CIRP, 50/1: 319-322.

[132] Ueda, K., Fujii, N., Hatono, I., Kobayashi, M., 2002, Facility Layout Planning Using SelfOrganization Method, Annals of the CIRP, 51/1: 399-402.

[133] Iwata, K., Onosato, M., Koike, M., 1994, Random Manufacturing System: a New Concept of Manufacturing Systems for Production to Order, Annals of the CIRP, 43/1: 379-382.

[134] Sluga, A., Butala, P., Peklenik, J., 2005, A Conceptual Framework for Collaborative Design and Operations of Manufacturing Work Systems, Annals of the CIRP, 50/1: 323-326.

[135] Ueda, K., Lengyel, A., Hatono, I., 2004, Emergent Synthesis Approaches to Control and Planning in Make to Order Manufacturing Environments, Annals of the CIRP, 53/1: 385-388.

[136] Eversheim, W., Hack, T., 1996, Managing Multiple Product Variants in Assembly Control with a Fuzzy Petri-Net Approach, Annals of CIRP, 45/1: 45-48.

[137] Noto la Diega, S., Passannanti, A., Perrone, G., 1995, Machining Economics in FMS by a Fuzzy Approach, Annals of the CIRP, 44/1: 417-420.

[138] Liu, F., Luh, P. B., Moser, B., Kegg, R. L., 1998, Scheduling and Coordination of Distributed Design Projects, Annals of the CIRP, 47/1: 111-114.

[139] Wilhelm, R. G., Chu, B., Sun, R., 2005, Electronic Commerce Negotiation in a Supply Chain via Constraint Evaluation, Annals of the CIRP, 54/1: 423-426. 
[140] Kjellberg, T., 1994, Product Modeling and Human Information Processing-A Cognitive Foundation, ESPRIT-CIME 10th Annual Conference, 117-121.

[141] Schuh, G., Eversheim, W., 2004, Release Engineering: An Approach to Control Rising SystemComplexity, Annals of the CIRP, 53/1: 167-170.

[142] ElMaraghy, H. A., Kuzgunkaya, O., Urbanic, R. J., 2004, Manufacturing Systems Configuration Complexity, Annals of the CIRP, 54/1: 445-448.

[143] Klein, H. K., D. L. Kleinman, 2002, The Social Construction of Technology: Structural Considerations, Science, Technology, and Human Values, 27/1: 28-52.

[144] Wood, D. J., Gray B., 1991, Toward a Comprehensive Theory of Collaboration, Journal of Applied Behavioral Science, 27/2.

[145] Bendy, G. Z., Seglin, M. H., Meister, D., 2000, Activity Theory: History, Research and Application, Theor. Issues in Ergonomics Science, 1/2: 168-206.

[146] Fjeld, M., Lauche, K., Bichsel, M., Voorhorst, F., Krueger, H., Rauterberg, M., 2002, Physical and Virtual Tools: Activity Theory Applied to the Design of Groupware, Computer Supported Cooperative Work, 11/7: 153-180.

[147] Cai, J., Lu, S. C.-Y., Grobler, F., Case, M., Jing N., 2005, Modeling and Managing Collaborative Processes over the Internet, Journal of Business Process Management, 11/3: 255-274.

[148] Mattessich, P. W., Murray-Close, M., Monsey, B. R., 2001, Collaboration: What Makes It Work, 2nd Edition: A Review of Research Literature on Factors Influencing Successful Collaboration, Amherst H. Wilder Foundation.

[149] Simon, H. A., 1997, Models of Bounded Rationality: Empirically Grounded Economic Reasoning, MIT Press, Cambridge, MA.

[150] Straus, D., Layton, T. C., 2002, How to Make Collaboration Work: Powerful Ways to Build Consensus, Solve Problems, and Make Decisions, Berrett-Koehler Publishers.

[151] Aronson, E., Wilson, T. D., Akert, R., 2006, Social Psychology, Prentice Hall.

[152] Fishburn, P. C., 1973, The Theory of Social Choice, Princeton University Press, Princeton, NJ.

[153] Arrow, K. J., 1959, Rational Choice Functions and Orderings, Economica, XXVI/102.

[154] Harsanyi, J. C., 1955, Cardinal Welfare, Individualistic Ethics, \& Interpersonal Comparisons of Utility, J. of Political Economy, 63/2: 309-321.

[155] Kenney, R. L., 1976, A Group Preference Axiomatization with Cardinal Utility, Management Science, 23/1: 140-145.

[156] Hammond, S., Keeney, R. L., Raiffa H., 2002, Smart Choices: A Practical Guide to Making Better Decisions, Broadway.

[157] Keeney, R. L., 1992, Value-Focused Thinking - A Path to Creative Decision Making, Harvard Press.

[158] Raiffa, H., 2002, Negotiation Analysis: The Science and Art of Collaborative Decision Making, Belknap Press of Harvard University Press, Cambridge, MA.

[159] Berger, P. L., Luckmann, T., 1966, The Social Construction of Reality: a Treatise in the Sociology of Knowledge, Anchor Books.

[160] Lu, S. C., Zhang, J., Wang, C., and Grobler, F., 2005, Modeling Design Processes and Stakeholder Perspectives to Support Collaborative Engineering Negotiation: A Case Study of Designing Individualized Prostheses over the Internet, International Journal of Computer Applications in Technology, 23/1: 2-12.

[161] Lu, S. C.-Y., 2006, The Scientific Roles of TRIZ in Innovative Engineering Design, the 2006 TRIZ-Future Conference, Kortrijk, Belgium. 
[162] Blinder, A. S., and Morgan, J., 2000, Are Two Heads Better Than One: an Experimental Analysis of Group vs. Individual Decision Making, NBER (National Bureau of Economic Research) Working Paper, September 2000.

[163] Lu, S. C.-Y., Conger, A., 2006, Supporting Participative Joint Decisions in Integrated Design and Manufacturing Teams, the 2006 International Integrated Design and Manufacturing in Mechanical Engineering Conference, Grenoble, France.

[164] Arias, E. E., H., Fischer, G., Gorman, A., Scharff, E., 2000, Transcending the Individual Human Mind: Creating Shared Understanding through Collaborative Design, ACM Transactions on Computer-Human Interaction, 7/1: 84-113.

[165] Hazelrigg, G. A., 1997, On Irrationality in Engineering Design, Journal of Mechanical Design, Transactions of the ASME, 119/4: 194-196.

[166] Lu, S. C.-Y., N. Jing, J. Y. Zhang, and A. Li, 2003, A Socio-Technical Framework to Support Collaborative Engineering Processes, Final Report to the U.S. Army Construction Engineering Research Laboratory, Los Angeles, CA.

[167] Bijker, W. E., P. Hughes, T. J. Pinch, 1987, The Social Construction of Technological Systems, MIT Press, Cambridge, MA.

[168] Cyert, R. M., March, J. G., 1992, A Behavioral Theory of the Firm, Blackwell.

[169] Searle, J. R., 1995, The Construction of Social Reality, Free Press, New York.

[170] Case, M., 1994, The Discourse Model for Collaborative Engineering Design: A Distributed and Asynchronous Approach, PhD Thesis, University of Illinois at Urbana-Champaign, Urbana, IL, Advisor: Lu, S. C.-Y.

[171] Heylighen, F., Joslyn, C., 2001, Cybernetics and Second-Order Cybernetics, Encyclopedia of Physical Science and Technology, Academic Press, NY, NY.

[172] Dorf, R. C., Bishop, R. H., 2000, Modern Control Systems, Prentice Hall, Inc., Upper Saddle River, New Jersey.

[173] Kossiakoff, A., Sweet, W. N., 2002, Systems Engineering Principles and Practice, Wiley.

[174] Dym, C. L., 2003, Engineering Design: A Project- Based Introduction, Wiley \& Sons.

[175] Cai, J., 2002, A Socio-Technical Approach to Support Collaborative Engineering Design, PhD Thesis, University of Southern California, Los Angeles, CA, Advisor: Lu, S. C.-Y.

[176] Pentland, A., Choudhury, T., Eagle, N., Singh, P., 2005, Human Dynamics: Computation for Organizations, Pattern Recognition, 26/2: 503-511. 